\title{
The Effects of Platycodin D, a Saponin Purified from Platycodi Radix, on Collagen-Induced DBA/1J Mouse Rheumatoid Arthritis
}

\author{
O. Gon Kwon, ${ }^{1}$ Sae Kwang Ku, ${ }^{2,3}$ Hee Duk An, ${ }^{1}$ and Young Joon Lee ${ }^{2,4}$ \\ ${ }^{1}$ Department of Rehabilitation Medicine, College of Korean Medicine, Daegu Haany University, \\ 1 Hannydaero, Gyeongsan, Gyeongsangbuk-Do 712-715, Republic of Korea \\ ${ }^{2}$ The Medical Research Center for Globalization of Herbal Medicine, College of Korean Medicine, Daegu Haany University, \\ 1 Hannydaero, Gyeongsan, Gyeongsangbuk-Do 712-715, Republic of Korea \\ ${ }^{3}$ Department of Histology and Anatomy, College of Korean Medicine, Daegu Haany University, 1 Hannydaero, \\ Gyeongsan, Gyeongsangbuk-Do 712-715, Republic of Korea \\ ${ }^{4}$ Department of Preventive Medicine, College of Korean Medicine, Daegu Haany University, 1 Hannydaero, \\ Gyeongsan, Gyeongsangbuk-Do 712-715, Republic of Korea
}

Correspondence should be addressed to Hee Duk An; okee@dhu.ac.kr and Young Joon Lee; gksxntk@dhu.ac.kr

Received 17 August 2013; Accepted 17 December 2013; Published 6 January 2014

Academic Editor: Vincenzo De Feo

Copyright (c) 2014 O. Gon Kwon et al. This is an open access article distributed under the Creative Commons Attribution License, which permits unrestricted use, distribution, and reproduction in any medium, provided the original work is properly cited.

\begin{abstract}
The object of this study is to observe the effects of platycodin D, a saponin purified from Platycodi Radix, on mice collageninduced arthritis (CIA). A daily dose of 200,100 , and $50 \mathrm{mg} / \mathrm{kg}$ platycodin D was administered orally to male DBA/1J mice for 40 days after initial collagen immunization. To ascertain the effects administering the collagen booster, CIA-related features (including body weight, poly-arthritis, knee and paw thickness, and paw weight increase) was measured from histopathological changes in the spleen, left popliteal lymph node, third digit, and the knee joint regions. CIA-related bone and cartilage damage improved significantly in the platycodin D-administered CIA mice. Additionally, myeloperoxidase (MPO) levels in the paw were reduced in platycodin D-treated CIA mice compared to CIA control groups. The level of malondialdehyde (MDA), an indicator of oxidative stress, decreased in a dose-dependent manner in the platycodin D group. Finally, the production of IL-6 and TNF$\alpha$, involved in rheumatoid arthritis pathogenesis, was suppressed by treatment with platycodin $\mathrm{D}$. Taken together, these results suggest that platycodin D is a promising new effective antirheumatoid arthritis agent, exerting anti-inflammatory, antioxidative and immunomodulatory effects in CIA mice.
\end{abstract}

\section{Introduction}

Rheumatoid arthritis (RA) is a common human autoimmune disease characterized by chronic inflammation of the synovial membranes with concomitant destruction of cartilage and bone. Although the etiology and pathogenesis of RA are not yet understood, it has been suggested that abnormalities of cytokines, such as interleukin (IL)-1, IL-6, and TNF- $\alpha$, play an important role in the pathogenesis [1]. In addition, the current view of the cytokine network in rheumatoid joints supports the notion that TNF- $\alpha$ activates a cytokine cascade characterized by the simultaneous production of proinflammatory cytokines such as IL-1 and IL-6 and of anti-inflammatory cytokines such as IL-10, IL-1Ra, and soluble TNF receptor [2]. In epidemiological studies, oxidative damage to proteins, lipids, DNA, cartilage, and extracellular collagen has been demonstrated in patients with RA [3] and moreover has demonstrated an inverse correlation between the dietary intake of antioxidants and the incidence of RA [4]. Lipid peroxidation markers such as serum malondialdehyde (MDA) and urine isoprostane are reported to be elevated in collagen-induced arthritis (CIA) compared with those in controls [5, 6]. As above concepts for pathogenesis of RA, clinical application with TNF- $\alpha$-neutralizing antibody and IL-1 receptor antagonist exhibits substantial efficacy but carries the disadvantages of high cost, hypersensitivity to 
medications, and possibility of serious infections $[7,8]$. In addition, antioxidants also showed favorable effects on the RA but their effects are much lower than the expectation $[9,10]$. Therefore, further efforts are necessary to develop new drugs with fewer side effects and much more potent for treatment of RA.

As increase of the concern in the functional food and wellbeing in life, the demands and consumption of functional food originated from natural sources are increased [12]. Platycodi Radix, the roots of Platycodon grandiflorum (Jacq.), has been used traditionally as an expectorant and a remedy for bronchitis, tonsillitis, laryngitis, and suppurative dermatitis in China, Korea, and Japan. In China and Korea, the fresh roots of $P$. grandiflorum have been eaten as pickles for preventing obesity [13]. Platycodin D is a major pharmacological constituent of Platycodi Radix [14], and it has been showen the antidiabetic [14-16], anti-inflammatory [17-19], anticancer $[20,21]$, antinociceptive $[22,23]$, and immunomodulatory $[24,25]$ activities.

The object of this study was, therefore, to evaluate the efficacy of platycodin D, a saponin purified from Platycodi Radix on mice CIA. In the present study, 50, 100, and $200 \mathrm{mg} / \mathrm{kg}$ of platycodin D were orally administered to male DBA/1J mice for 40 days, once a day from the initial collagen immunization. The changes on the body weight, clinical scores, thicknesses of left knee and paw, spleen, left popliteal lymph node and left hid paw weights, paw myeloperoxidase (MPO; for neutrophil infiltration) and malondialdehyde (MDA; for oxidative stress) contents, paw TNF- $\alpha$ and interleukin (IL)- 6 levels, splenocytes TNF- $\alpha$ and IL- 6 productions and histopathology of spleen, left popliteal lymph node, third digits, and knee joint regions were monitored using established methods. Nonimmunized and nonboosted mice were used as a normal control, and Enbrel, TNF- $\alpha$ neutralizing antibody, was used as reference substances in this study.

\section{Materials and Methods}

2.1. Animals and Husbandry. Forty-eight males DBA/ 1JJmsSlc (5-week-old upon receipt; SLC, Japan) were used after acclimatization for 14 days. Animals were housed four or five per polycarbonate cage in a temperature $\left(20-25^{\circ} \mathrm{C}\right)$ - and humidity (40-45\%)-controlled room with a $12 \mathrm{hrs:12 \textrm {hrs }}$ light: dark cycle. Feed (Samyang, Korea) and water were supplied ad libitum. All animals were fasted overnight before at immunization and sacrifice (about $18 \mathrm{hrs}$ with ad libitum access to water) and treated according to the Guide for the Care and Use of Laboratory Animals [26]. In this study, eight mice per groups, total 6 groups, were divided.

2.2. Preparations and Administration of Test Materials. The platycodin D, gift from Glucan Corp. Ltd (Korea), was extracted from Platycodi Radix by previous method [11]. The raw sample $(100 \mathrm{~kg})$ of platycodin radix was extracted with methanol and partitioned sequentially with n-hexane, chloroform, ethyl acetate, and n-butanol. The n-butanol fraction was then subjected to Diaion HP-20 resin (Mitsubishi, Japan), and the fractions eluted at $60-80 \%$ of methanol were collected to obtain $90 \mathrm{~g}$ of crude saponins. The crude saponins were further purified by repeated silica gel (Merck, Germany) chromatography to obtain the purified platycodin $\mathrm{D}$. The process was repeated several times until a sufficient quantity of platycodin $\mathrm{D}$ was obtained. The purified platycodin $\mathrm{D}$ was identified on the basis of Rf, FAB-MS (=1225.38), and $\left[{ }_{13} \mathrm{C}\right]-\mathrm{NMR}$ spectra compared with the authentic platycodin $\mathrm{D}$ (Figure 1). Prepared platycodin D is light yellow powder and is stored in a desiccator to be protected from light and humidity. Platycodin D is well dissolved (clear light yellow solution) at least $40 \mathrm{mg} / \mathrm{mL}$ concentrations in distilled water. Enbrel (Wyeth Korea, Korea) $25 \mathrm{mg} / 0.5 \mathrm{~mL}$ vehicle packed in syringe was purchase from local supplier.

In this study, we selected $200 \mathrm{mg} / \mathrm{kg}$ of platycodin D as the highest dosage, and 100 and $50 \mathrm{mg} / \mathrm{kg}$ were selected as the middle and lowest dosages using common ratio 2 . In addition, $10 \mathrm{mg} / \mathrm{kg}$ Enbrel, TNF- $\alpha$ neutralizing antibody, (injected three day-intervals) was used as reference drug. In the present study, 200, 100, and $50 \mathrm{mg} / \mathrm{kg}$ of platycodin $\mathrm{D}$ were orally administered, once a day 40 days in a volume of $5 \mathrm{~mL} / \mathrm{kg}$ of distilled water. In case of Enbrel, it subcutaneously injected three day-intervals from immunization to sacrifice diluted using saline at $10 \mathrm{mg} / \mathrm{kg}$ levels. In intact and CIA control, only distilled water was orally administered instead of test materials, once a day for 40 days from immunization.

2.3. Induction of CIA. CIA was induced according to the previous methods [27]. Mice were immunized intradermally at the base of tail with $100 \mu \mathrm{g}$ of type II collagen (Chondrex, WA, USA) emulsified with an equal volume of Freund's complete adjuvant (Chondrex, WA, USA) and intraperitoneally boosted with type II collagen ( $100 \mu \mathrm{g}$ in $0.05 \mathrm{M}$ acetic acid) emulsified with an equal volume of Freund's incomplete adjuvant (Chondrex, WA, USA) at 23 days after the initial immunization. In intact control mice, only vehicle, $0.05 \mathrm{M}$ acetic acid was intradermally injected instead of collagen immunization and intraperitoneally administered instead of antigen boosting, respectively.

2.4. Changes in Body Weights. Changes of body weight were calculated at 1 day before immunization (Day -1), at immunization (Day 0), 1, 7, 14, 21, 23 (at antigen boosting), 28,35 , and 39 days after immunization with at a termination using an automatic electronic balance (Precisa Instrument, Switzerland). At immunization (initiation of administration) and at a termination, all experimental animals were overnight fasted (water was not; about $12 \mathrm{hr}$ ) to reduce the differences from feeding.

2.5. Estimation of Clinical Arthritis Indexes in CIA. The clinical severity of arthritis in all four paws of mice was evaluated in a triple-blind fashion by a previous published scoring system [28]. Briefly, 0: normal; 1: mild, apparent swelling limited to individual digits; 2: moderate, redness, and swelling of the ankle; 3: redness and swelling of the paw including digits; and 4: maximally inflamed limb with involvement of multiple joints. The arthritis score for each mouse was the sum of four paws, with the highest score of 16 for each mouse and recorded at antigen boosting (Day 23), $24,25,26,27,30,33,36,39$, and 40 days after immunization. 


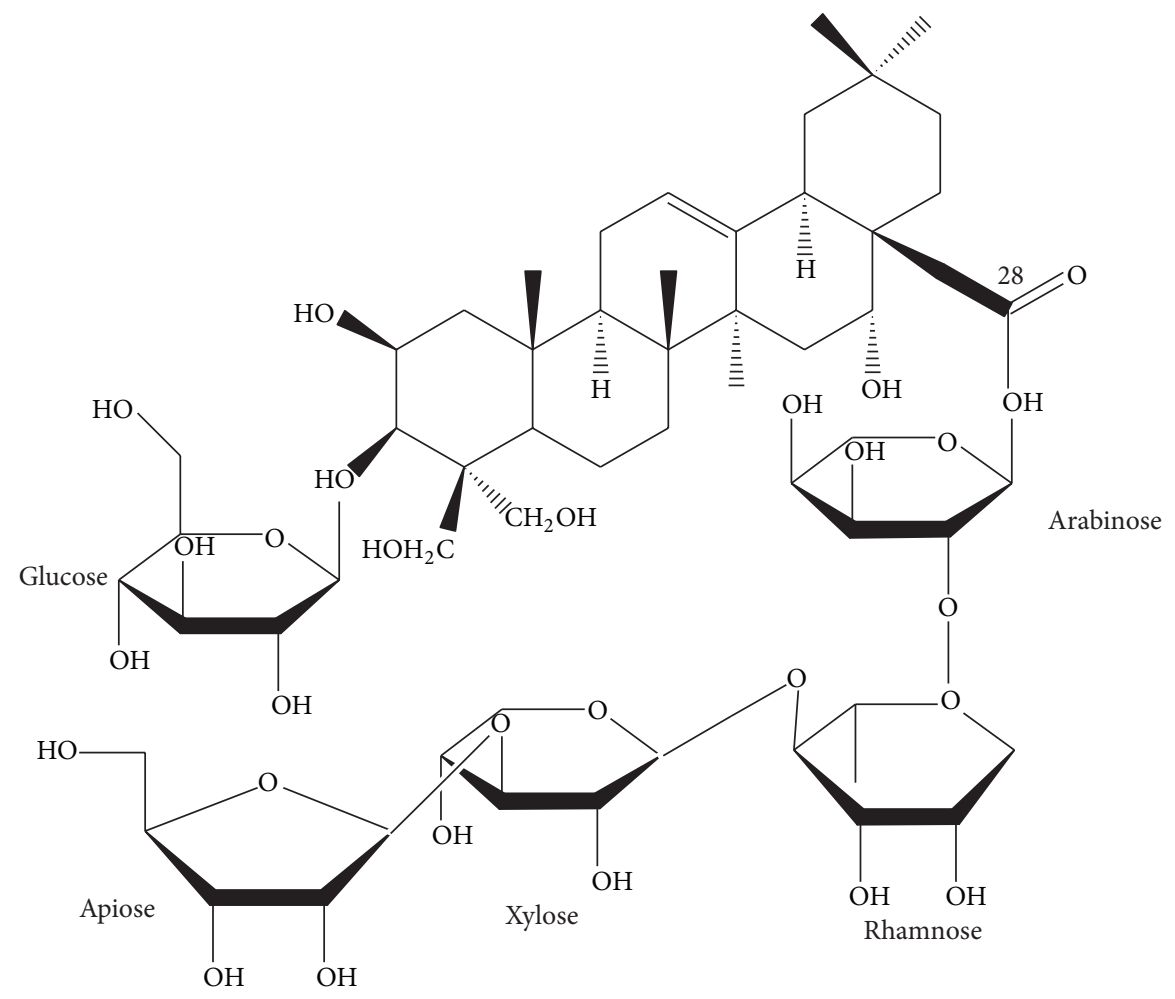

FIGURE 1: Chemical structure of platycodin D used in this study. Platycodin D is a triterpenoid bidesmoside, composed of an aglycone moiety, 3-Glc, and 28-O-Api-Xyl-Rha-Ara [11].

2.6. Paw and Knee Thickness Measurement. The thickness of left hind paw and knee was measured using an electronic digital caliper (Mitutoyo, Japan) and recorded at antigen boosting (Day 23), 24, 25, 26, 27, 30, 33, 36 and 39 days after immunization. In addition, to reduce the individual differences from start of measurements, the changes after antigen challenges were also calculated.

2.7. Organ Weight Measurements. At sacrifice, the spleen, left hind paw and left popliteal lymph nodes were collected after connective tissues, muscles, and debris were removed. The weight of organs or paw was calculated at g levels regarding absolute wet-weights. To reduce the individual body weight differences, the relative weight (\%) was calculated using body weight at sacrifice and absolute weight.

2.8. Measurement of MPO Contents. Collected paws were homogenized $(50 \mathrm{mg} / \mathrm{mL})$ in $0.5 \%$ hexadecyltrimethylammonium bromide (Sigma, MO, USA) in $10 \mathrm{mM} \mathrm{3-N-mor-}$ pholinopropanesulfonic acid (Sigma, MO, USA) and centrifuged at $15,000 \mathrm{~g}$ for $40 \mathrm{~min}$. The suspension was then sonicated three times for 30 seconds. An aliquot of supernatant $(20 \mu \mathrm{L})$ was mixed with a solution of $1.6 \mathrm{mM}$ tetra-methylbenzidine (Wako, Japan) and $1 \mathrm{mM}$ hydrogen peroxide (Daejung, Korea). Activity was measured spectrophotometrically as the change in absorbance at $650 \mathrm{~nm}$ at $37^{\circ} \mathrm{C}$, using a microplate reader [29]. Results are expressed as milliunits $(\mathrm{mU})$ of MPO activity per $\mathrm{mg}$ of protein, which were determined with the Bradford assay [30].
2.9. Measurement of MDA Contents. MDA formation was utilized to quantify the lipid peroxidation in the mouse paws and measured as thiobarbituric acid-reactive material. Tissues were homogenized $(100 \mathrm{mg} / \mathrm{mL})$ in $1.15 \% \mathrm{KCl}$ buffer. Two hundred microliters of the homogenates were then added to a reaction mixture consisting of $1.5 \mathrm{~mL} 0.8 \%$ thiobarbituric acid (Sigma, MO, USA), $200 \mu \mathrm{L} 8.1 \%$ sodium

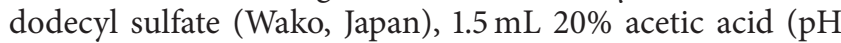
3.5), and $600 \mu \mathrm{L}$ distilled water. The mixture was then heated at $90^{\circ} \mathrm{C}$ for $45 \mathrm{~min}$. After cooling to room temperature, the samples were cleared by centrifugation $(10,000 \mathrm{~g}$ for $10 \mathrm{~min})$ and their absorbance measured at $532 \mathrm{~nm}$, using 1,1,3,3tetramethoxypropane as an external standard [29]. The level of lipid peroxides was expressed as nmol of $\mathrm{MDA} / \mathrm{mg}$ of protein.

2.10. Measurement of Paw Cytokine Contents. Paws were snap frozen in liquid nitrogen; the sample was then homogenized in $700 \mu \mathrm{L}$ of a TRIS-HCl buffer containing protease inhibitors. Samples were centrifuged for $30 \mathrm{~min}$ and the supernatant was frozen at $-80^{\circ} \mathrm{C}$ until assay. Cytokine levels were determined using commercial ELISA kit [31].

2.11. Measurement of Splenocyte Cytokine Productions. Mouse spleens were collected for cell preparation and washed twice with PBS. The spleens were minced and the red blood cells were lysed with $0.83 \%$ ammonium chloride (Daejung, Korea). The cells were filtered through a cell strainer and 
centrifuged at $1300 \mathrm{rpm}$ at $4^{\circ} \mathrm{C}$ for $5 \mathrm{~min}$. The cell pellets were resuspended in RPMI 1640 medium and plated in 24well plates (Corning, NY, USA) at a concentration of $1 \times 10^{6}$ cells/well. Isolated splenocytes were cultured for $72 \mathrm{~h}$. The amounts of TNF- $\alpha$ and IL- 6 in the culture supernatants were measured by ELISA [32]. The amounts of cytokines present in the test samples were determined from standard curves constructed with serial dilutions of recombinant murine TNF- $\alpha$ and IL-6. The absorbance was determined with an ELISA microplate reader at $405 \mathrm{~nm}$.

2.12. Histopathology. The knee joints parts were sampled with the joint capsules preservation with total left hind paw and fixed in $10 \%$ neutral buffered formalin. After 5 days of fixation, they were decalcified using decalcifying solution ( $24.4 \%$ formic acid and $0.5 \mathrm{~N}$ sodium hydroxide) for 5 days (mixed decalcifying solution was exchanged once a day for 5 days). After that, median joint parts were longitudinally trimmed or third digits were crossly trimmed, and embedded in paraffin, sectioned $(3 \sim 4 \mu \mathrm{m})$ and stained with hematoxylin and eosin (H\&E). The histological profiles of the knee joints and third digits were observed as compared with the intact control. In addition, spleen and left popliteal lymph nodes were sampled and fixed in 10\% neutral buffered formalin. After paraffin embedding, 3-4 $\mu \mathrm{m}$ sections were prepared. Representative sections were stained H\&E for light microscopical examination. After that the histological profiles of individual organs were observed.

Histomorphometry. The thickness of articular surface (including compact bone and articular cartilages) of tibia and femur ( $\mu \mathrm{m} /$ bone), articular cartilage thickness of tibia and femur ( $\mu \mathrm{m} /$ bone), infiltrated inflammatory cell numbers of left knee cavity and cutaneous regions of third digits (cells $/ \mathrm{mm}^{2}$ ), dorsum digit skin thicknesses around third digits ( $\mu \mathrm{m} /$ digit), and cortical bone thickness of third digits $(\mu \mathrm{m} /$ digit $)$ were measured as histomorphometrical analyses at prepared knee joint and third digit samples for RA analysis using digital image analyzer (DMI-300, DMI, Korea). In addition, total (central regions; $\mathrm{mm} / \mathrm{spleen})$ and white pulp $(\mathrm{mm} / \mathrm{pulp})$ thicknesses of spleen with numbers of white pulp (pulps $/ \mathrm{mm}^{2}$ ) and total (central regions) and cortex thicknesses ( $\mathrm{mm} / \mathrm{lymph}$ node) of left popliteal lymph were measured as histomorphometrical analyses for immune response at prepared spleen and thymus samples using digital image analyzer according to the previous report [33]. The histopathologist was blinds to group distribution when this analysis was made.

2.13. Statistical Analyses. Multiple comparison tests for different dose groups were conducted. Variance homogeneity was examined using the Levene test. If the Levene test indicated no significant deviations from variance homogeneity, the obtained data were analyzed by one way ANOVA test followed by least-significant differences (LSD) multicomparison test to determine which pairs of group comparison were significantly different. In case of significant deviations from variance homogeneity being observed at Levene test, a nonparametric comparison test, Kruskal-Wallis $\mathrm{H}$ test was

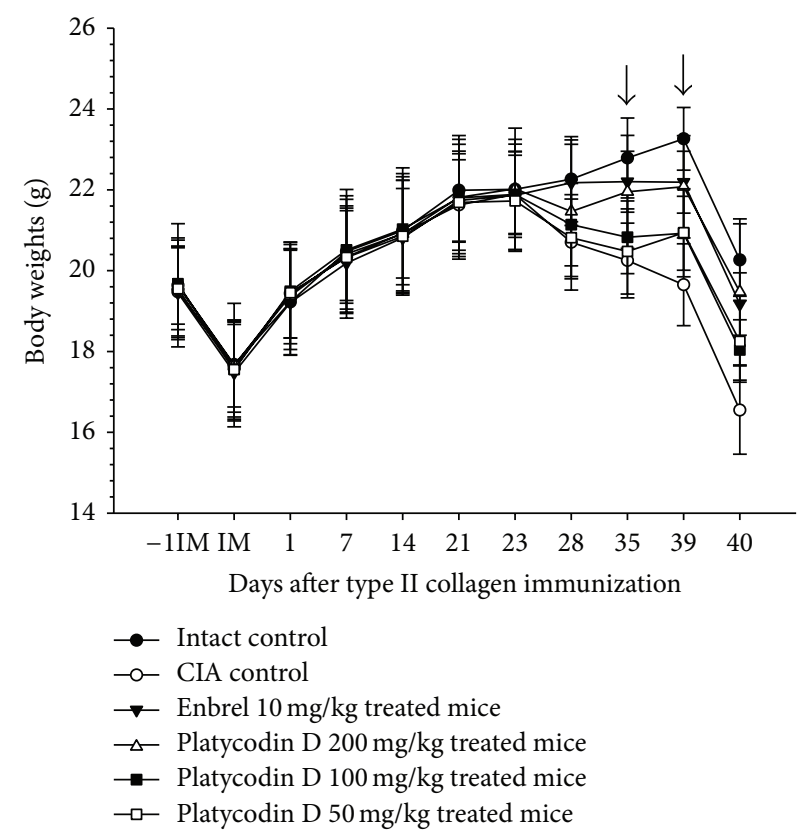

Figure 2: Platycodin D inhibited changes in body weight in CIA mice. Values are expressed as means \pm SD $(n=8)$; platycodin D $200 \mathrm{mg} / \mathrm{kg}$ treated mice showed significant $(P<0.01)$ increases of body weight from 35 days after treatment, platycodin D 100 and $50 \mathrm{mg} / \mathrm{kg}$ treated mice showed significant $(P<0.01)$ increases of body weight from 39 days after treatment, respectively (dot arrow). CIA, collagen-induced arthritis; -1IM, 1 day before immunization; IM, immunization (start of administration of test materials); 23, day of antigen challenge. All animals were fasted overnight before immunization and sacrifice (40 days after immunization).

conducted. When a significant difference is observed in the Kruskal-Wallis $\mathrm{H}$ test, the Mann-Whitney $U$ (MW) test was conducted to determine the specific pairs of group comparison, which are significantly different. Statistical analyses were conducted using SPSS for Windows (Release 12.0K, SPSS Inc., USA).

\section{Results}

3.1. Changes in Body Weight. Significant decreases of body weight were detected from 28 days after immunization (5 days after antigen boosting) in CIA control as compared with intact control. Body weight gains were also significantly decreased after antigen boosting and during experimental periods. However, the body weight of Enbrel mice and mice treated with the three dosages of platycodin D increased markedly from 28 days after immunizations, as did the body weights after antigen boosting and during experimental periods (Figure 2).

3.2. Therapeutic Effects on Rheumatoid Arthritis. Clinical arthritis scores were significantly higher from 24 days after immunization (1 day after antigen boosting) in CIA control compared with intact control. However, significant decreases in clinical arthritis scores were detected from 25 days after 


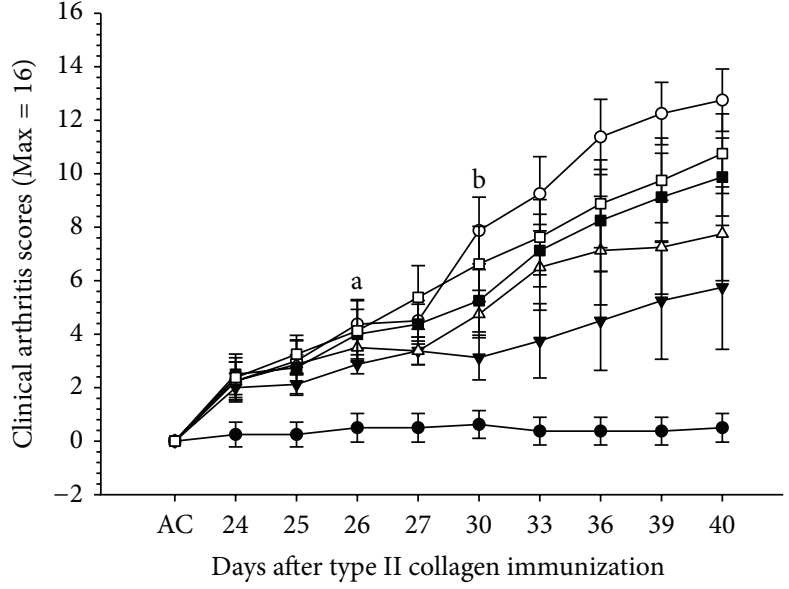

(a)

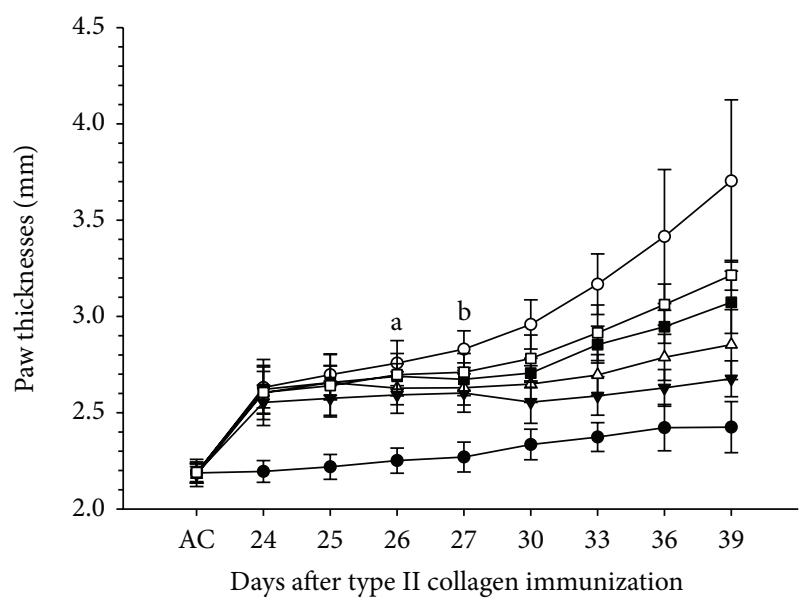

(b)

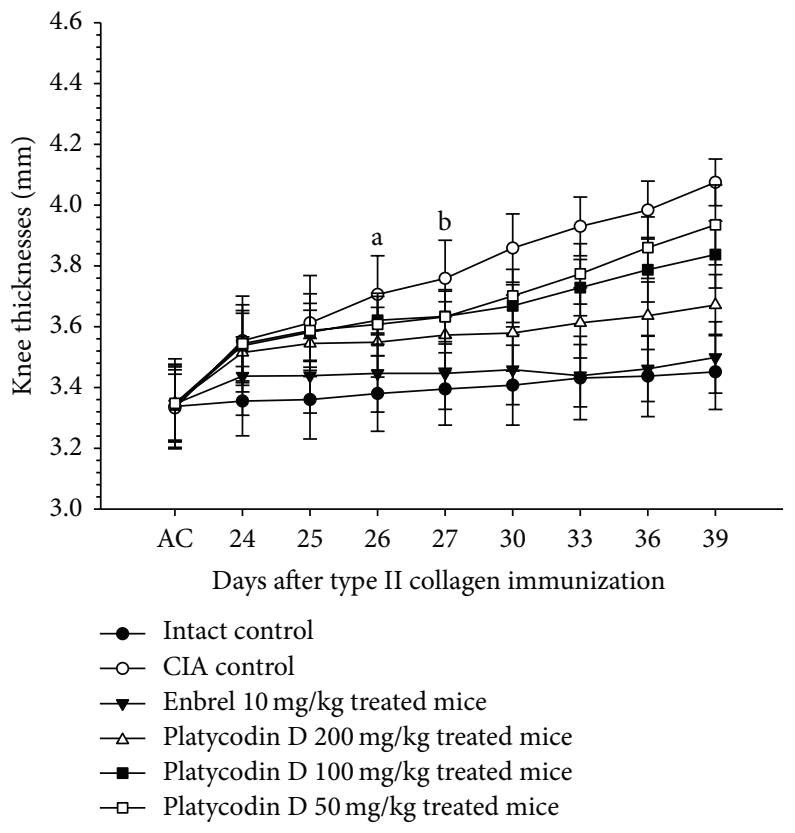

(c)

Figure 3: Platycodin D reduced clinical arthritis scores and paw and knee thickness in platycodin D-treated CIA mice. (a) Decreases of clinical arthritis scores were detected in platycodin D treated mice as compared with CIA control mice. (b) Paw thickness was reduced in platycodin D treated mice as compared with CIA control mice. (c) Knee thickness was reduced in platycodin D treated mice as compared with CIA control mice. Values are expressed as means $\pm \mathrm{SD}(n=8) ;{ }^{\mathrm{a}} \mathrm{P}<0.05$ in platycodin D $200 \mathrm{mg} / \mathrm{kg}$ treated mice, ${ }^{\mathrm{b}}$ in platycodin D 100 and $50 \mathrm{mg} / \mathrm{kg}$ treated mice as compared with CIA control mice. AC: day of antigen challenge at 23 days after immunization. All animals were fasted overnight before immunization.

immunization in Enbrel, from 26 days after immunization in platycodin $\mathrm{D} 200 \mathrm{mg} / \mathrm{kg}$ treated mice, and from 30 days after immunization in platycodin D 100 and $50 \mathrm{mg} / \mathrm{kg}$ treated mice as compared with CIA control mice, respectively (Figure 3(a)).

There were a significant increases in paw thicknesses and knee thickness from 24 days after immunization (1 day after antigen boosting) in CIA control as compared with intact control. Paw and knee thickness after antigen challenges were also increased significantly.

Paw thickness in Enbrel and $200 \mathrm{mg} / \mathrm{kg}$ platycodin D treated mice were decreased significantly from 25 and 26 days after immunizations, respectively. Mice treated with 100 and $50 \mathrm{mg} / \mathrm{kg}$ platycodin $\mathrm{D}$ also exhibited decreased paw thickness from 27 days after immunization. In addition, after antigen challenge, paw thickness decreased in Enbrel group, and in all three platycodin D-treated groups, as compared with the CIA control (Figure 3(b)).

Knee thickness in Enbrel and $200 \mathrm{mg} / \mathrm{kg}$ platycodin D treated mice decreased significantly from 25 and 26 days after immunizations, respectively, and from 27 days after immunization in 100 and $50 \mathrm{mg} / \mathrm{kg}$ platycodin D-treated mice as compared with CIA control mice. The changes on the knee thicknesses after antigen challenges were also 


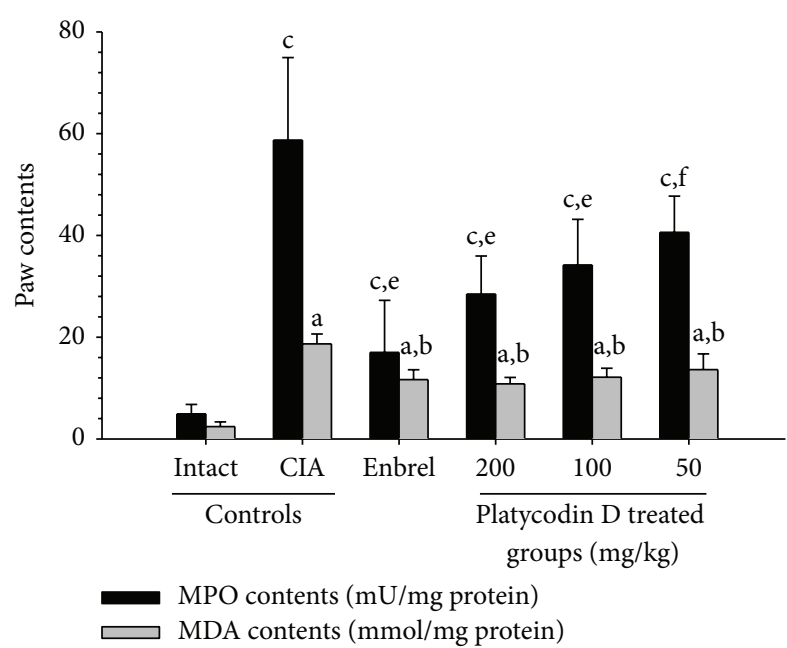

(a)

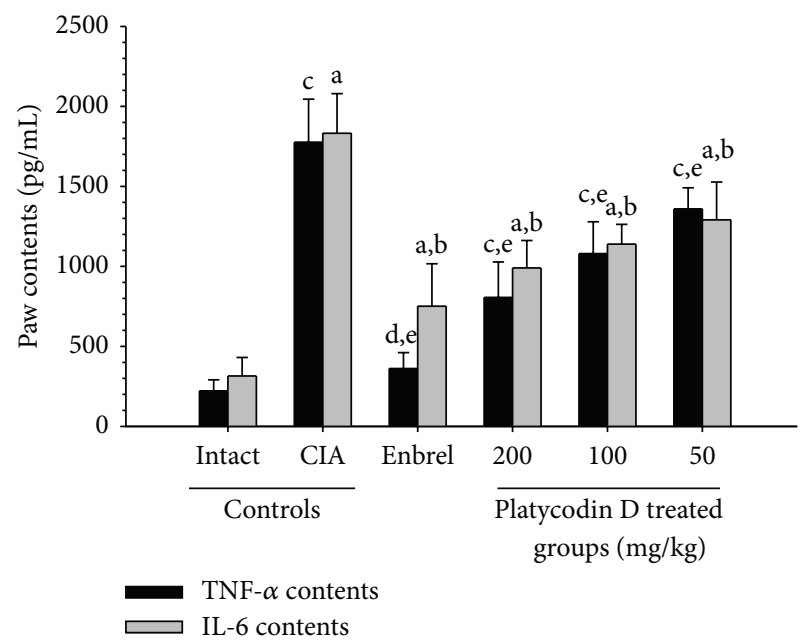

(b)

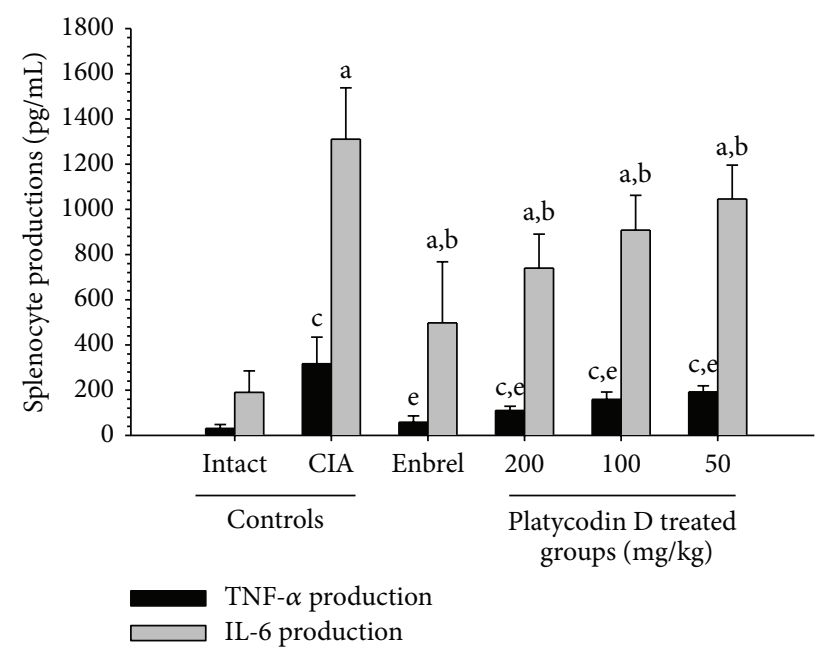

(c)

Figure 4: Platycodin D had a therapeutic effect on the CIA mice mediated by anti-inflammatory, antioxidative, and immunomodulatory effects. (a) Paw MPO and MDA contents of platycodin D-treated mice were lower compared to CIA control mice. (b) Paw TNF- $\alpha$ and IL-6 levels in platycodin D-treated mice were lower compared with CIA control mice. (c) Splenocyte TNF- $\alpha$ and IL-6 levels in platycodin D-treated mice were lower compared with CIA control mice. Values are expressed as means $\pm \mathrm{SD}(n=8)$; ${ }^{\mathrm{a}} \mathrm{P}<0.01$ as compared with intact control by LSD test; ${ }^{\mathrm{b}} P<0.01$ as compared with CIA control by LSD test; ${ }^{\mathrm{c}} P<0.01$ and ${ }^{\mathrm{d}} P<0.05$ as compared with intact control by MW test; ${ }^{\mathrm{e}} P<0.01$ and ${ }^{\mathrm{f}} P<0.05$ as compared with CIA control by MW test.

significantly decreased in Enbrel and all three different dosages of platycodin $\mathrm{D}$ treated mice as compared with CIA control (Figure 3(c)).

The absolute and relative weights of the left paw, spleen, and left popliteal lymph nodes were significantly increases in CIA control, compared with the intact control. However, in the Enbrel treated group, and in all three different dosages of platycodin D treated groups, these weights were lower than in the CIA control group (Table 1).

3.3. Anti-Inflammatory and Immunomodulatory Effects of Platycodin D. MPO and MDA contents in right hind paw were higher in CIA control as compared with intact control at sacrifice, respectively. However these paw MPO and MDA contents of Enbrel and all three different dosages of platycodin D treated group were significantly decreased as compared with CIA control mice, respectively (Figure 4(a)).

There was significant increment of TNF- $\alpha$ and IL- 6 contents in right hind paw were detected in CIA control as compared with intact control at sacrifice. In addition, splenocyte TNF- $\alpha$ and IL- 6 productions increased in the CIA control compared with the intact control.

However, for the Enbrel group, and all three different dosages of platycodin $\mathrm{D}$ treated group were significantly lower as compared with CIA control mice (Figures 4(b) and $4(\mathrm{c})$ ).

3.4. Histopathological Changes in the Knee and Third Digits. Marked decreases in articular cartilages and bones surfaces were detected in both knee articular, femur, and tibia surfaces, 
TABLE 1: Changes of left hind paw and secondary lymphatic organs detected after treatment of Enbrel and three different dosages of platycodin $\mathrm{D}$ in CIA mice.

\begin{tabular}{|c|c|c|c|c|c|c|}
\hline \multirow{2}{*}{ Groups } & \multicolumn{2}{|c|}{ Paw weights } & \multicolumn{2}{|c|}{ Spleen weights } & \multicolumn{2}{|c|}{ Left popliteal lymph nodes weights } \\
\hline & Absolute & Relative & Absolute & Relative & Absolute & Relative \\
\hline \multicolumn{7}{|l|}{ Controls } \\
\hline Intact & $0.133 \pm 0.008$ & $0.667 \pm 0.022$ & $0.047 \pm 0.008$ & $0.236 \pm 0.028$ & $0.003 \pm 0.002$ & $0.013 \pm 0.009$ \\
\hline CIA & $0.202 \pm 0.027^{\mathrm{a}}$ & $1.195 \pm 0.188^{\mathrm{a}}$ & $0.101 \pm 0.009^{\mathrm{a}}$ & $0.599 \pm 0.075^{\mathrm{a}}$ & $0.015 \pm 0.004^{\mathrm{a}}$ & $0.088 \pm 0.025^{\mathrm{a}}$ \\
\hline \multicolumn{7}{|l|}{ Reference } \\
\hline Enbrel & $0.136 \pm 0.004^{c}$ & $0.665 \pm 0.037^{\mathrm{c}}$ & $0.062 \pm 0.004^{\mathrm{ac}}$ & $0.302 \pm 0.022^{\mathrm{ac}}$ & $0.005 \pm 0.004^{c}$ & $0.025 \pm 0.020^{\mathrm{c}}$ \\
\hline \multicolumn{7}{|l|}{ Platycodin D } \\
\hline $200 \mathrm{mg} / \mathrm{kg}$ & $0.128 \pm 0.011^{c}$ & $0.688 \pm 0.121^{c}$ & $0.055 \pm 0.003^{\mathrm{bc}}$ & $0.291 \pm 0.022^{\mathrm{ac}}$ & $0.007 \pm 0.003^{b c}$ & $0.036 \pm 0.017^{\mathrm{bc}}$ \\
\hline $100 \mathrm{mg} / \mathrm{kg}$ & $0.140 \pm 0.018^{c}$ & $0.763 \pm 0.144^{\mathrm{c}}$ & $0.062 \pm 0.008^{\mathrm{ac}}$ & $0.335 \pm 0.047^{\mathrm{ac}}$ & $0.008 \pm 0.003^{\mathrm{ac}}$ & $0.041 \pm 0.015^{\mathrm{ac}}$ \\
\hline $50 \mathrm{mg} / \mathrm{kg}$ & $0.154 \pm 0.029^{\mathrm{d}}$ & $0.902 \pm 0.243^{\mathrm{bd}}$ & $0.074 \pm 0.019^{\mathrm{ad}}$ & $0.435 \pm 0.141^{\mathrm{ad}}$ & $0.011 \pm 0.003^{\mathrm{ac}}$ & $0.061 \pm 0.017^{\mathrm{ac}}$ \\
\hline
\end{tabular}

Values are expressed as mean $\pm \mathrm{SD}, \mathrm{g}$ (absolute weight), or \% (relative weights versus body weights at sacrifice) of eight mice. ${ }^{\mathrm{a}} P<0.01$ as compared with intact control by LSD test, ${ }^{\mathrm{b}} P<0.01$ and ${ }^{\mathrm{c}} P<0.05$ as compared with CIA control by LSD test, and ${ }^{\mathrm{d}} P<0.01$ as compared with intact control by MW test.

where there was marked inflammatory cell infiltration into the synovial cavity in the CIA control mice. There were also dramatic edematous changes, inflammatory cell infiltrations, and erosive damages of digital bones on the third digits of the CIA control mice. However, these classic histopathological changes indicative of CIA were dramatically decreased by treatment of Enbrel and all three different dosages of platycodin D, respectively (Figures 5 and 6).

The semiquantitative scores in the femur, tibia, and third digits of the CIA control group were increased significantly compared with the intact control. However these scores of Enbrel and all platycodin D treated mice were significantly decreased compared with CIA control mice (Figure 7(a)).

Knee articular surface thickness, including compact bone and cartilage, and knee articular cartilage thickness were significantly less in the femur and tibia of the CIA control compared with the intact control, whereas the thickness of these sites in the ENBREL and platycodin D-treated mice were markedly higher than in CIA control mice (Figures 7(b) and $7(\mathrm{c}))$.

The numbers of inflammatory cells infiltrated into the knee synovial cavity and third digits were significantly changed by platycodin D treatment. Significantly higher numbers of inflammatory cells infiltrated the knee synovial cavity and third digit cutaneous regions in the CIA control mice compared with the intact control; however, in the ENBREL and platycodin D-treated mice the numbers of infiltrated cells were lower compared with the CIA control mice (Figure $7(\mathrm{~d})$ ).

Significant increases of the third digit dorsum pedis skin and cortical thickness thicknesses were detected in platycodin $\mathrm{D}$ treated mice. The third digit dorsum pedis skin thicknesses was significantly higher in the CIA control; however there were significant decreases in the Enbrel, platycodin D-treated mice compared with the CIA control mice (Figure $7(\mathrm{e})$ ).

3.5. Histopathological Changes of Secondary Lymphatic Organs. Marked enlargement of spleen and popliteal lymph nodes were detected in CIA control mice. It is related to hyperplasia of lymphoid cells in the white pulp of spleen or cortex of lymph nodes. However, these histopathological changes of immune enhances were dramatically decreased by treatment of Enbrel and platycodin D (Figures 8 and 9). Also, total spleen thicknesses (around central regions; from apex to base), splenic white pulp numbers, splenic white pulp thickness, and popliteal lymph node total thickness were significantly lower in the Enbrel and platycodin D-treated mice compared with the CIA control mice (Figure 10).

\section{Discussion}

According to the results, platycodin $\mathrm{D}$ significantly improved CIA-related features, including poly-arthritis [34], body weight fluctuation $[35,36]$, knee and paw thickness, and paw weight increases [35]. These results suggested that platycodin D possesses an anti-inflammatory effect resulted from its antioxidant properties, since RA is a common human autoimmune disease characterized by chronic inflammation of the synovial membranes with concomitant destruction of cartilage and bone [1-6].

A marked reduction of body weights and gains have been detected in CIA mice after antigen exposures $[35,36]$, and significant decreases of body weights and gains were also detected in this study. However, these CIA related body weight and gain decreases were dose-dependently inhibited by treatment of platycodin $\mathrm{D}$ in this study. It is considered as one of the predictable evidence that platycodin $\mathrm{D}$ has favorable effects on the RA related body weight losses.

RA is characterized by the inflammation of synovial joints infiltrated by CD4+ T cells, macrophages, and plasma cells, neutrophils that play major roles in the pathogenesis of the disease $[2,37]$. Besides their direct damaging effects on tissues, it is well established that oxygen metabolites play a role in the recruitment of neutrophils, preferentially polymorphoneutrophils (PMNs), into injured tissues [38]. Activated PMNs are also a potential source of oxygen metabolites [39] and MPO is one of activating cytotoxic 


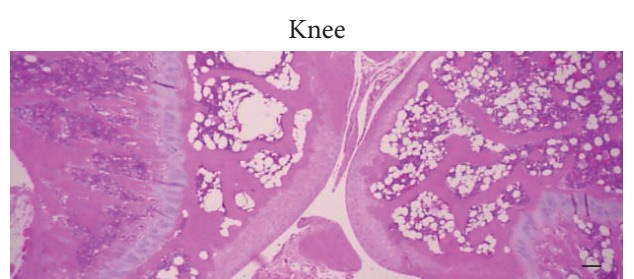

(a)

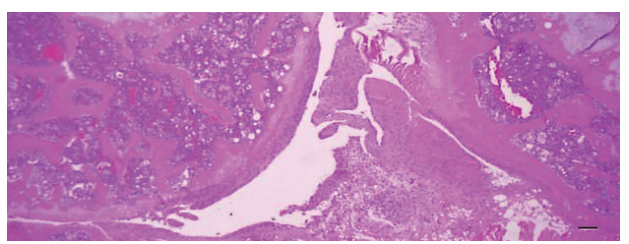

(e)

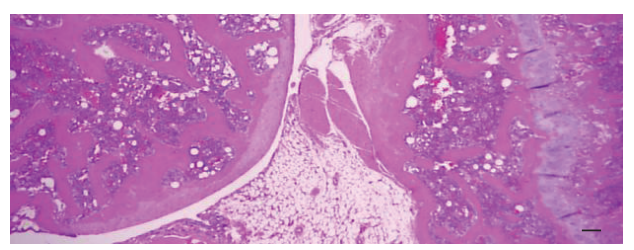

(i)

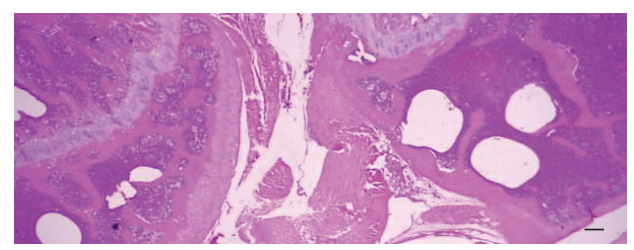

(m)

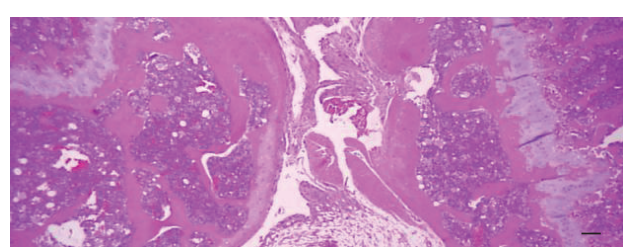

(q)

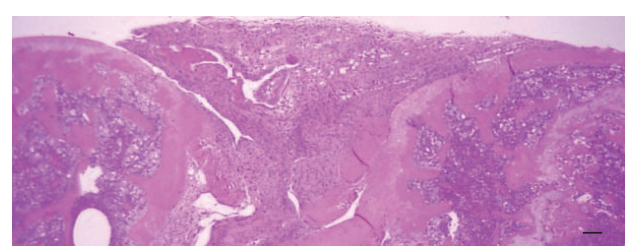

(u)

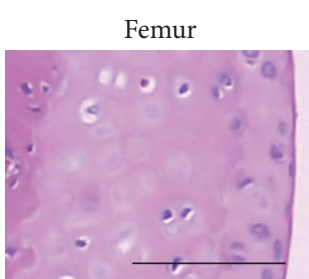

(b)

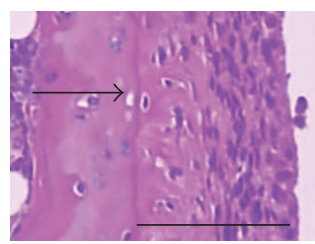

(f)

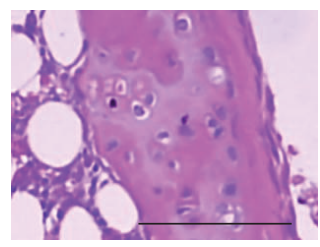

(j)

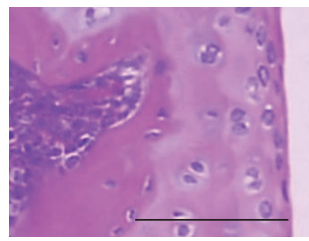

(n)

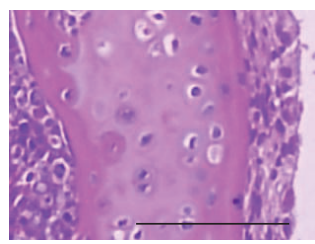

(r)

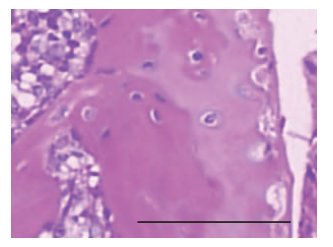

(v)

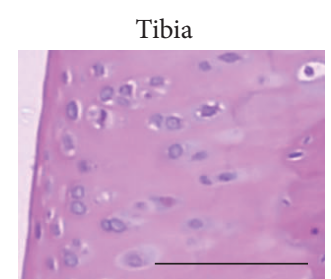

(c)

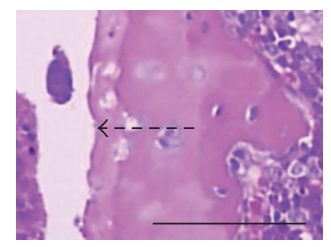

$(\mathrm{g})$

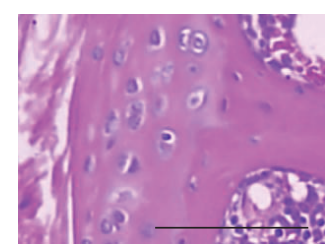

(k)

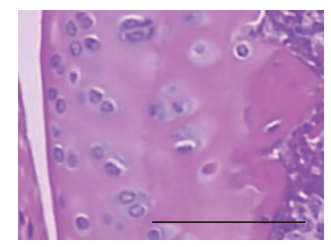

(o)

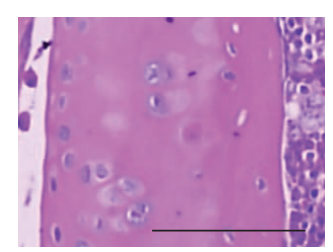

(s)

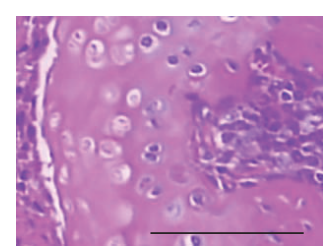

(w)

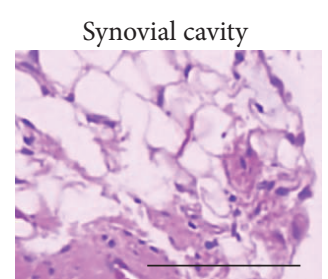

(d)

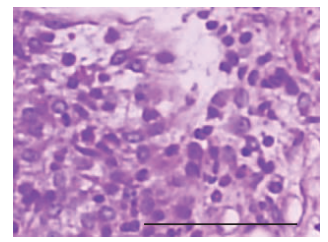

(h)

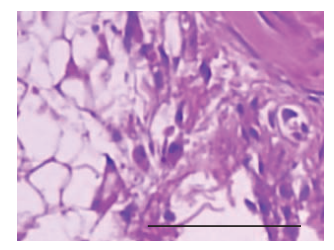

(l)

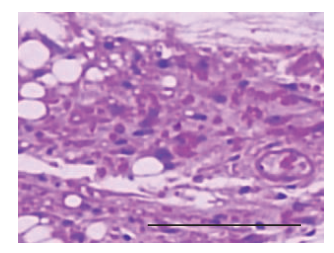

(p)

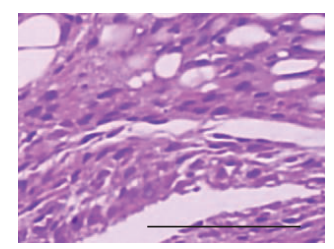

(t)

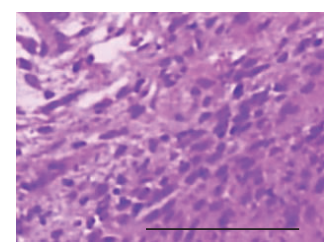

(x)

FIGURE 5: Histopathological profiles of the knee in the intact control ((a)-(d)), CIA control ((e)-(h)), Enbrel group ((i)-(l)), platycodin Dtreated groups; $200 \mathrm{mg} / \mathrm{kg}((\mathrm{m})-(\mathrm{p})), 100 \mathrm{mg} / \mathrm{kg}((\mathrm{q})-(\mathrm{t}))$, and $50 \mathrm{mg} / \mathrm{kg}((\mathrm{u})-(\mathrm{x}))$. Marked decreases in the articular surfaces (cartilage and bone) were detected in the knee articular surfaces of the femur and tibia, with severe inflammatory cell infiltration into the synovial cavity in the CIA control mice. However, histopathological changes in the CIA group were decreased dramatically by treatment with platycodin D. The arrow indicates articular surface thickness. Dotted arrow indicates articular cartilage thickness. All were stained with H\&E. Scale bars $=$ $160 \mu \mathrm{m}$. 


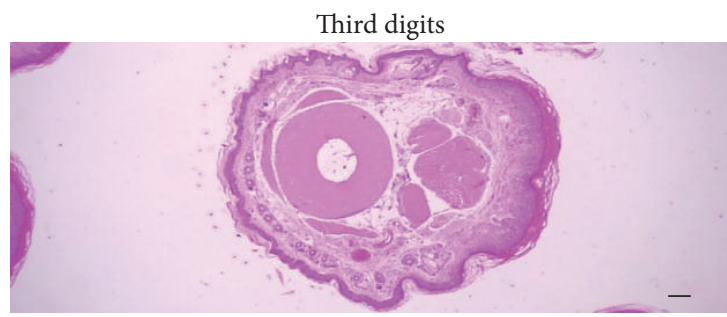

(a)

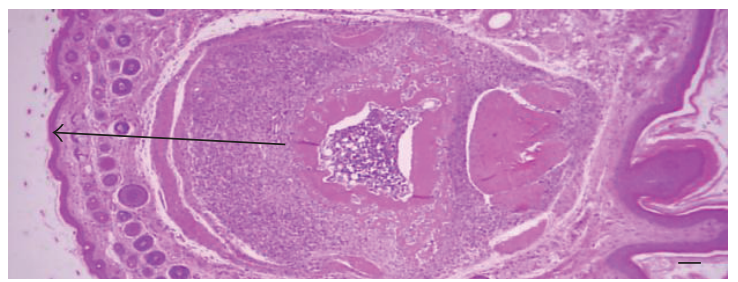

(d)

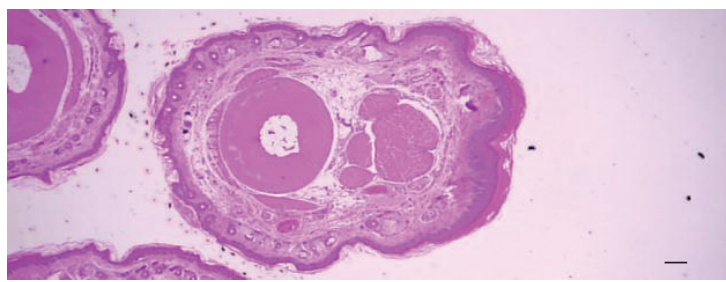

(g)

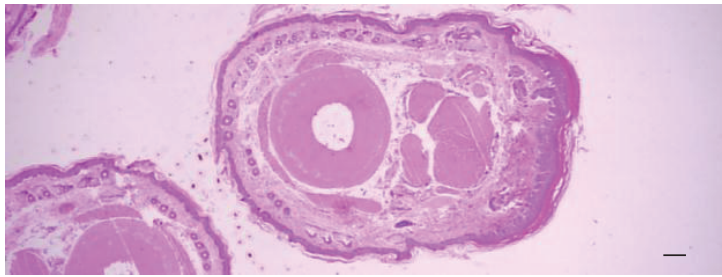

(j)

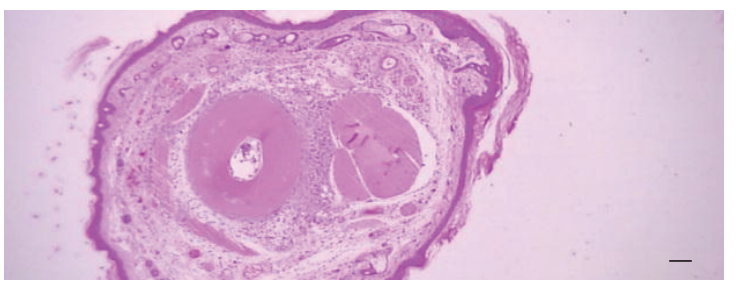

(m)

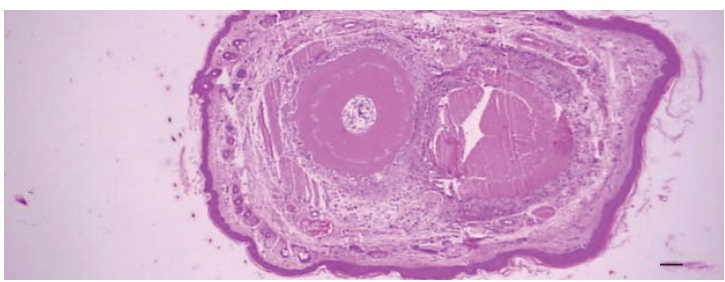

(p)

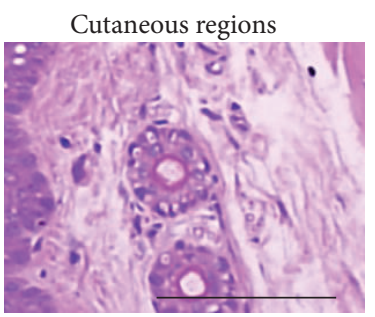

(b)

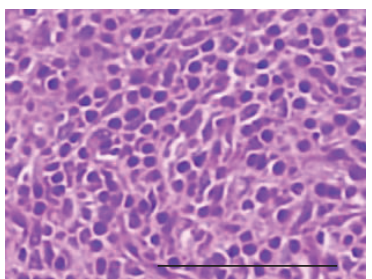

(e)

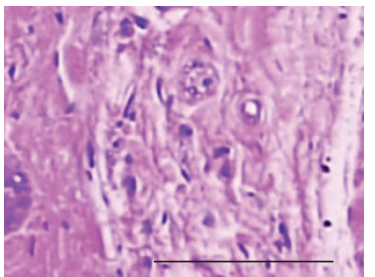

(h)

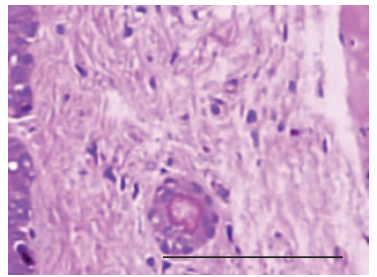

(k)

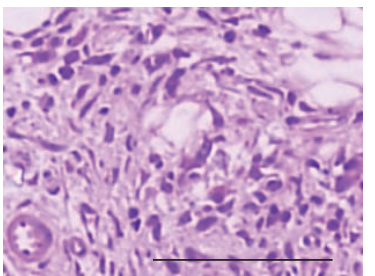

(n)

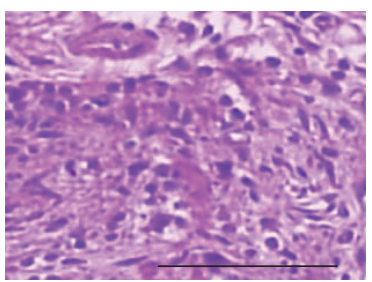

(q)

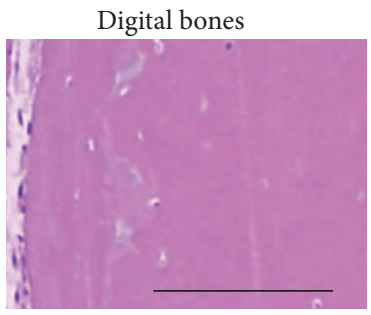

(c)

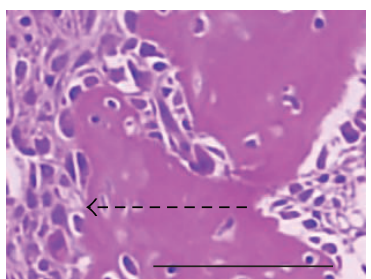

(f)

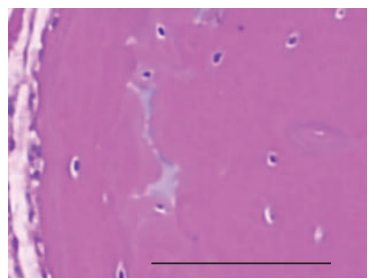

(i)

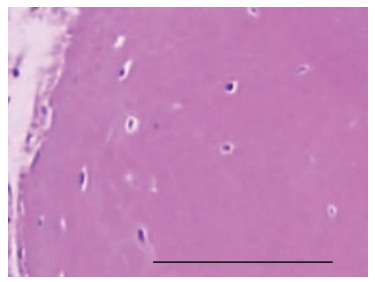

(l)

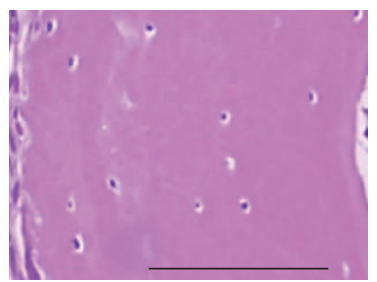

(o)

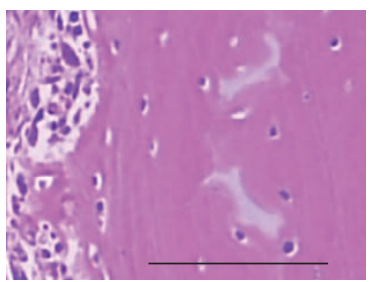

(r)

Figure 6: Histopathological profiles of the third digits in the intact control ((a)-(c)), CIA control ((d)-(f)), Enbrel group ((g)-(i)), platycodin D-treated groups; $200 \mathrm{mg} / \mathrm{kg}((\mathrm{j})-(\mathrm{l})), 100 \mathrm{mg} / \mathrm{kg}((\mathrm{m})-(\mathrm{o}))$, and $50 \mathrm{mg} / \mathrm{kg}((\mathrm{p})-(\mathrm{r}))$. Marked edematous changes, inflammatory cell infiltration, and erosive damage of digital bones were detected on the third digits of the CIA control mice. However, these histopathological changes were decreased dramatically by treatment with platycodin D. The arrow indicates the dorsum paw skin thickness. Doted arrow indicates cortical bone thickness. All were stained with H\&E. Scale bars $=160 \mu \mathrm{m}$. 


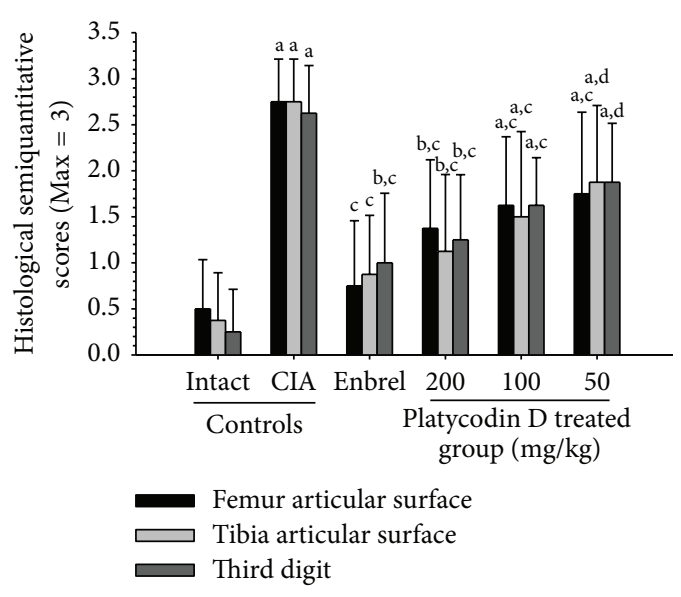

(a)

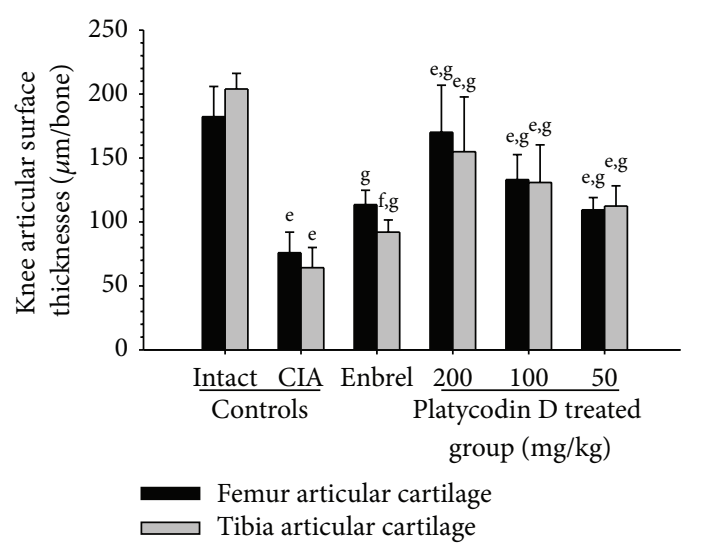

(c)

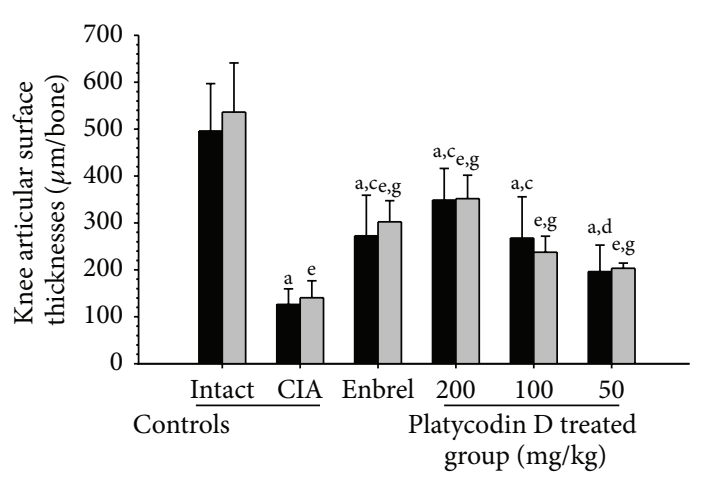

Femur articular surface Tibia articular surface

(b)

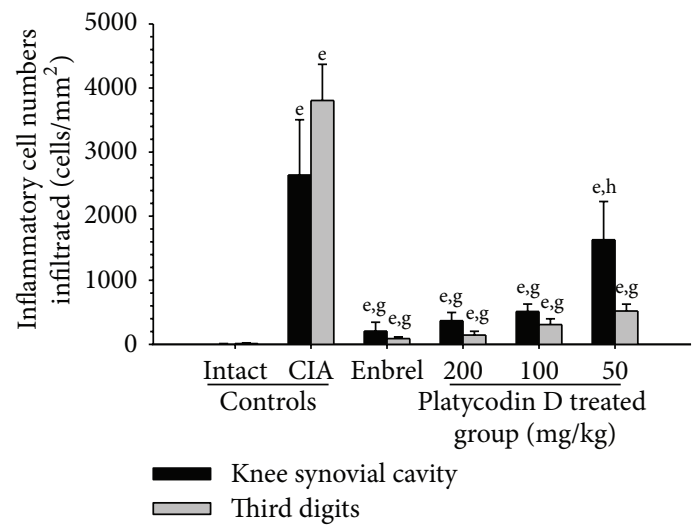

(d)

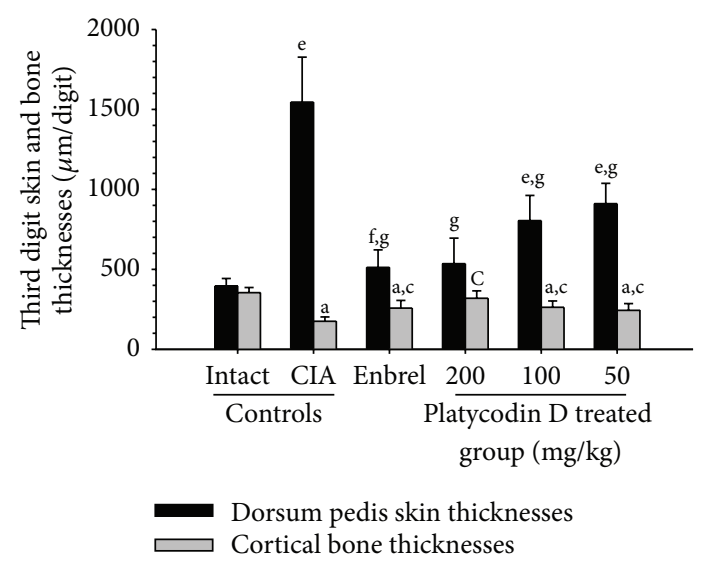

(e)

FIGURE 7: Platycodin D ameliorated the histopathological changes of the knee and third digit. (a) The semiquantitative scores of platycodin D-treated mice were lower compared with the CIA control mice. (b) The knee articular surface thickness of platycodin D-treated mice was greater compared with the CIA control mice. Knee articular surface thicknesses are shown in Figure 5 (arrow). (c) The knee articular cartilage thickness of platycodin D-treated mice was greater compared with the CIA control mice. Knee articular cartilage thicknesses are shown in Figure 5 (dotted arrow). (d) Infiltrated inflammatory cells of platycodin D-treated mice were lower compared with the CIA control mice (e). Increases in the third digit dorsum pedis skin thickness and decreases in the cortical bone thickness were inhibited by treatment with platycodin D compared with the CIA control mice. Measurements of the third digit dorsum pedis skin (arrow) and cortical bone (dotted arrow) thicknesses are shown in Figure 6. Values are expressed as means \pm SD $(n=8)$; ${ }^{\mathrm{a}} P<0.01$ and ${ }^{\mathrm{b}} P<0.05$ as compared with intact control by LSD test; ${ }^{\mathrm{c}} P<0.01$ and ${ }^{\mathrm{d}} P<0.05$ as compared with CIA control by LSD test; ${ }^{\mathrm{e}} P<0.01$ and ${ }^{\mathrm{f}} P<0.05$ as compared with intact control by MW test; ${ }^{\mathrm{g}} \mathrm{P}<0.01$ and ${ }^{\mathrm{h}} P<0.05$ as compared with CIA control by MW test. 


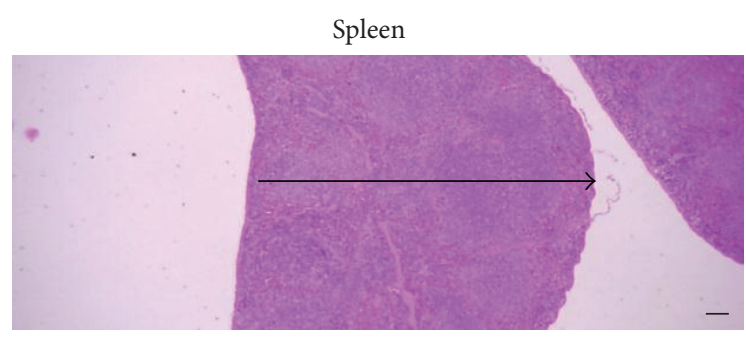

(a)

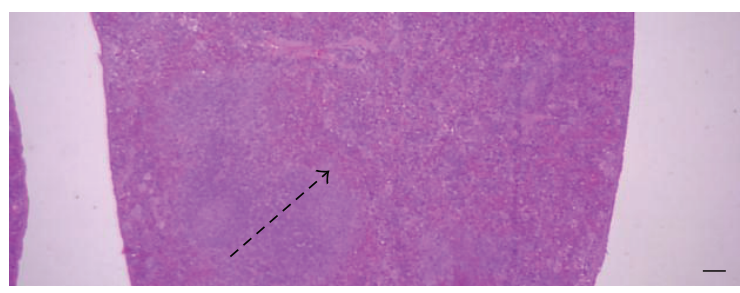

(c)

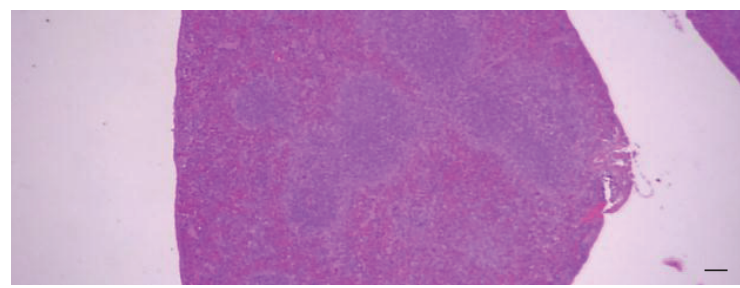

(e)

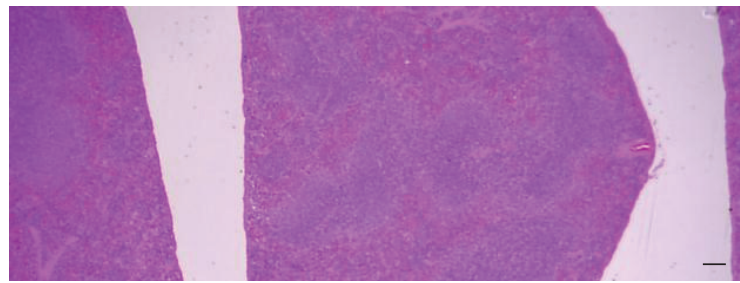

(g)

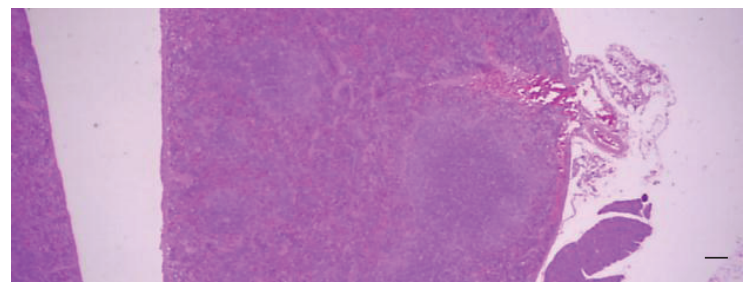

(i)

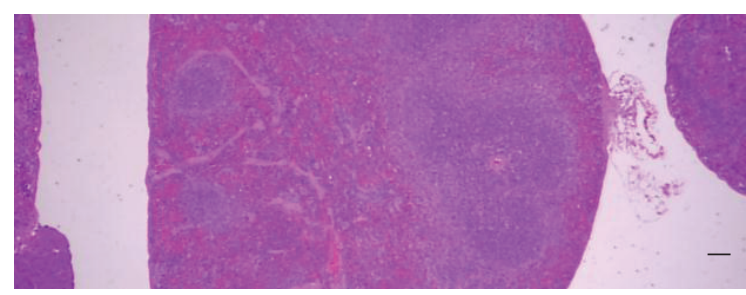

(k)

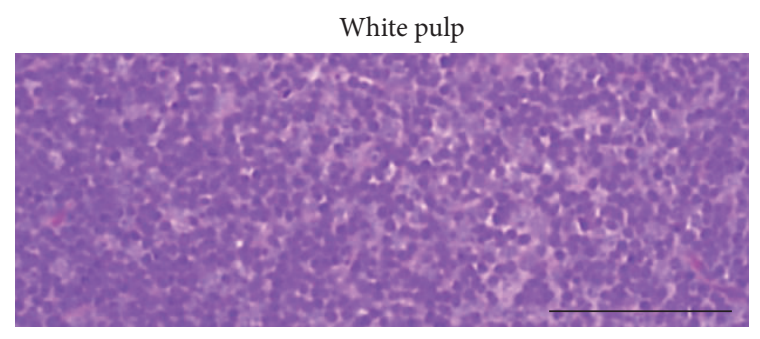

(b)

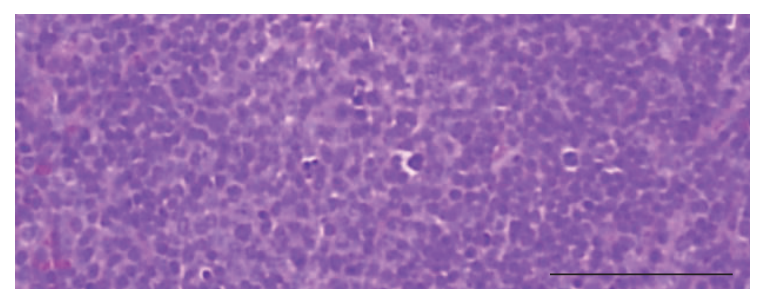

(d)

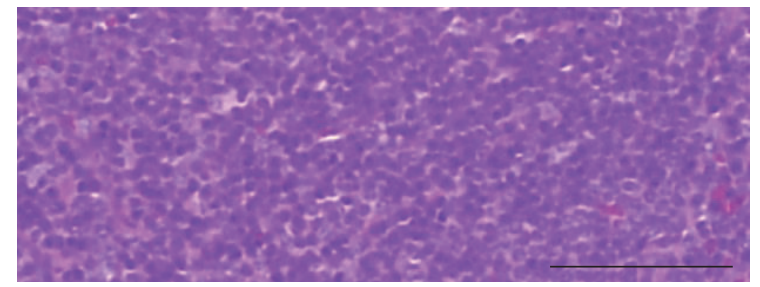

(f)

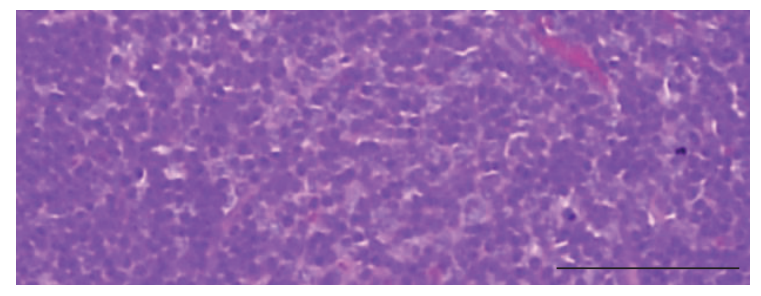

(h)

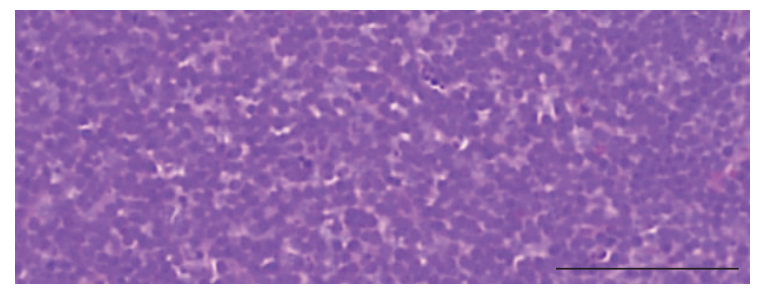

(j)

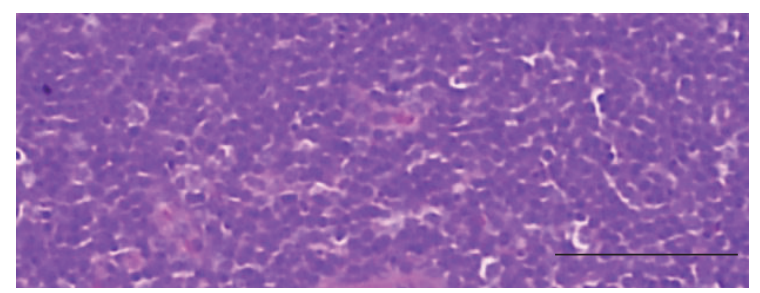

(l)

Figure 8: Histopathological profiles of the spleen in the intact control ((a), (b)), CIA control ((c), (d)), Enbrel group ((e), (f)), and platycodin D-treated groups; $200 \mathrm{mg} / \mathrm{kg}((\mathrm{g}),(\mathrm{h})), 100 \mathrm{mg} / \mathrm{kg}((\mathrm{i}),(\mathrm{j}))$, and $50 \mathrm{mg} / \mathrm{kg}((\mathrm{k}),(\mathrm{l}))$. Marked enlargement of the spleen, related to hyperplasia of lymphoid cells in the white pulp, was detected in the CIA control mice. However, these histopathological changes decreased dramatically after treatment with Enbrel and all three doses of platycodin D. Arrow indicates the total spleen thickness. Doted arrow indicates white pulp. All were stained with H\&E. Scale bars $=160 \mu \mathrm{m}$. 


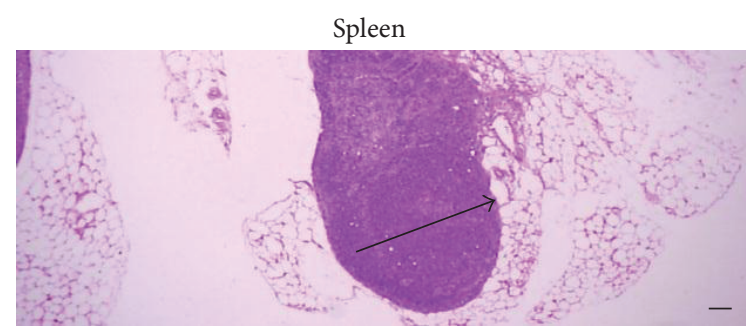

(a)

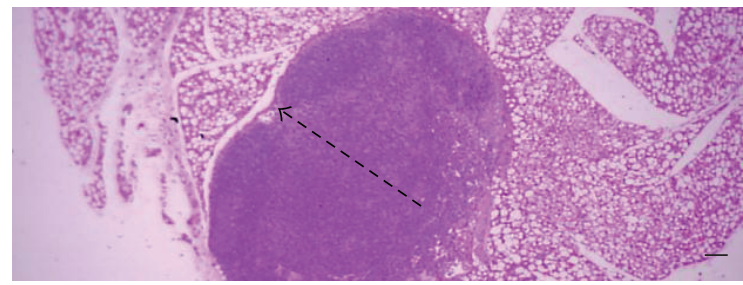

(c)

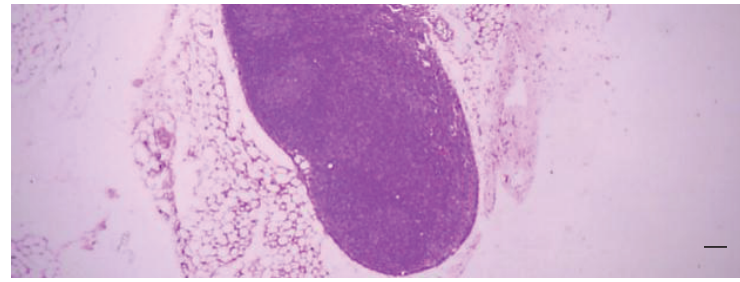

(e)

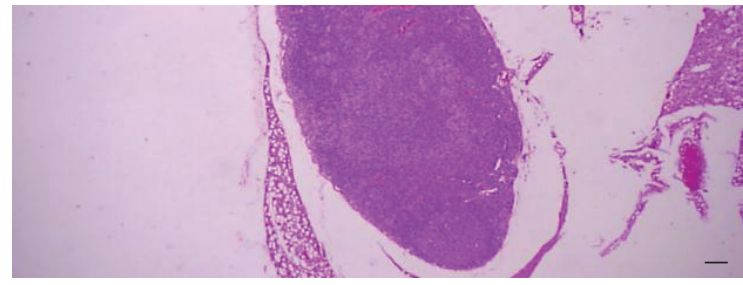

(g)

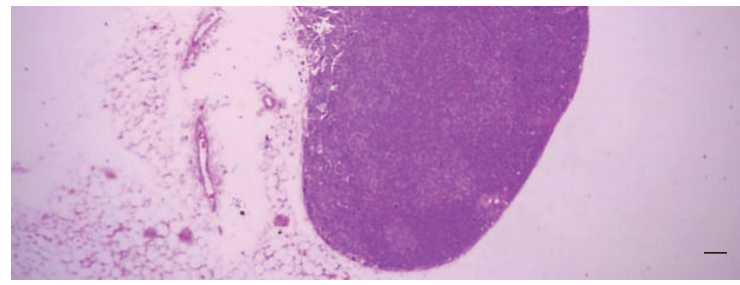

(i)

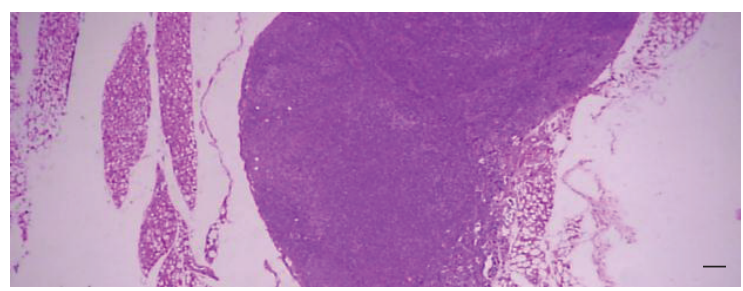

(k)

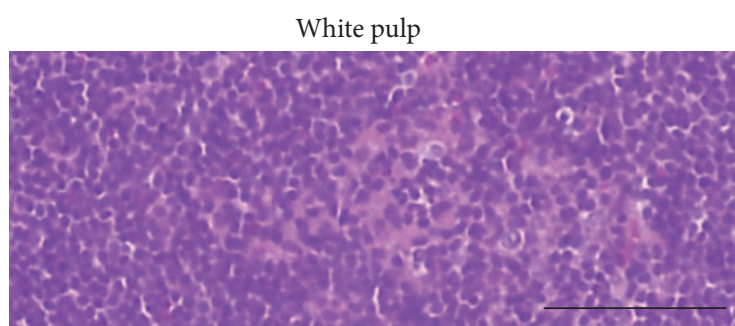

(b)

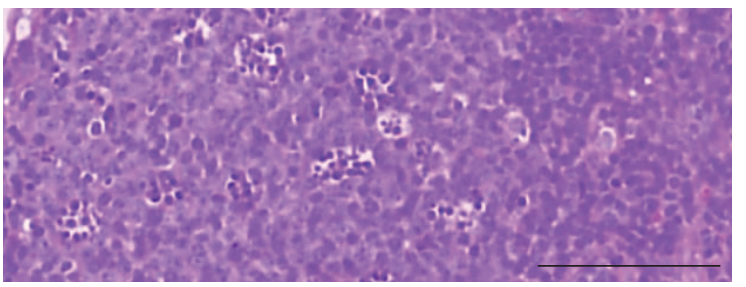

(d)

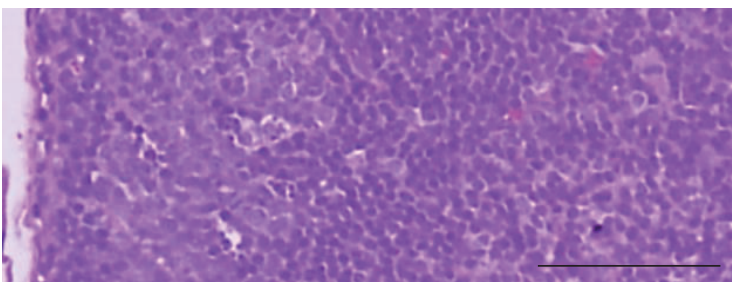

(f)

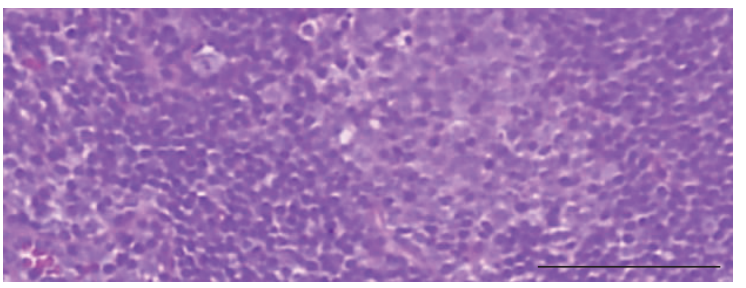

(h)

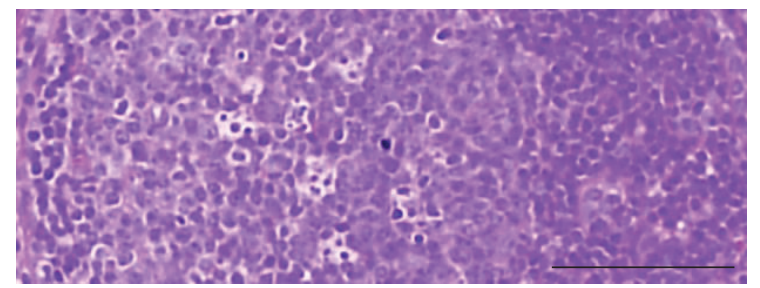

(j)

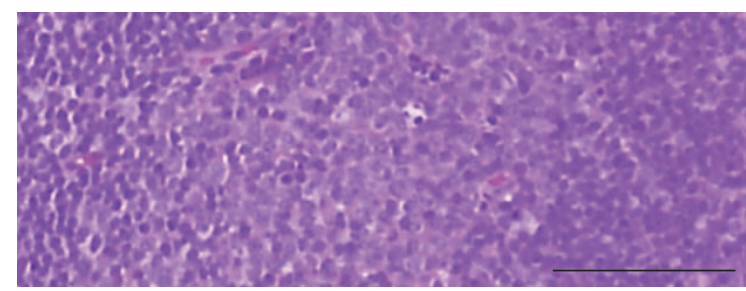

(l)

FIGURE 9: Histopathological profiles of the left popliteal lymph nodes in the intact control group ((a), (b)), CIA control group ((c), (d)), Enbrel group ((e), (f)), and platycodin D-treated groups; $200 \mathrm{mg} / \mathrm{kg}((\mathrm{g}),(\mathrm{h})), 100 \mathrm{mg} / \mathrm{kg}((\mathrm{i}),(\mathrm{j}))$, and $50 \mathrm{mg} / \mathrm{kg}((\mathrm{k})$, (l)). Marked enlargement of popliteal lymph nodes, related to hyperplasia of lymphoid cells in the cortex of the lymph nodes, was detected in the CIA control mice. However, these histopathological changes decreased dramatically after treatment with Enbrel and all three doses of platycodin D. Arrow indicates the total popliteal lymph node thickness. Doted arrow indicates cortex thicknesses. All were stained with H\&E. Scale bars $=160 \mu \mathrm{m}$. 


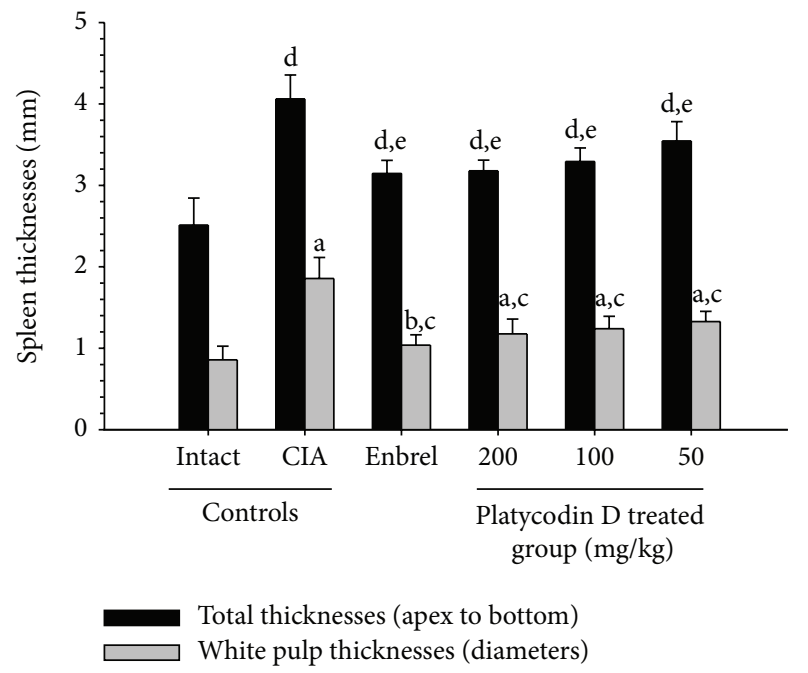

(a)

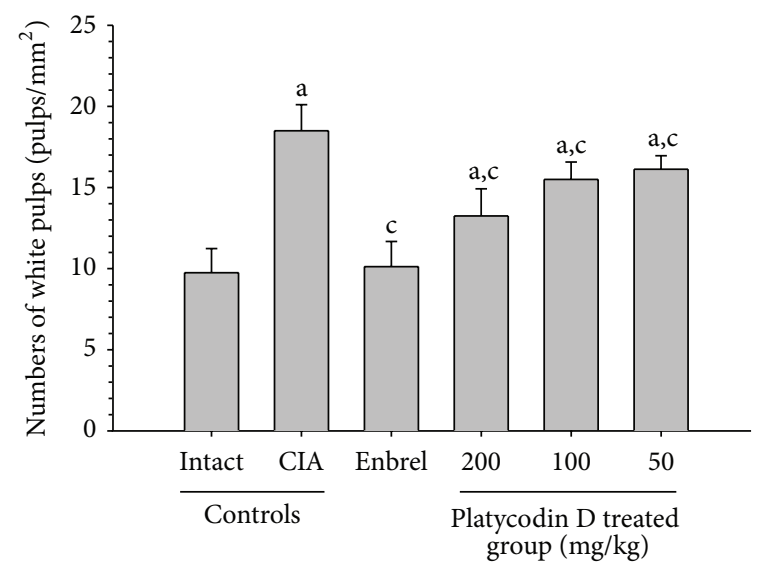

(b)

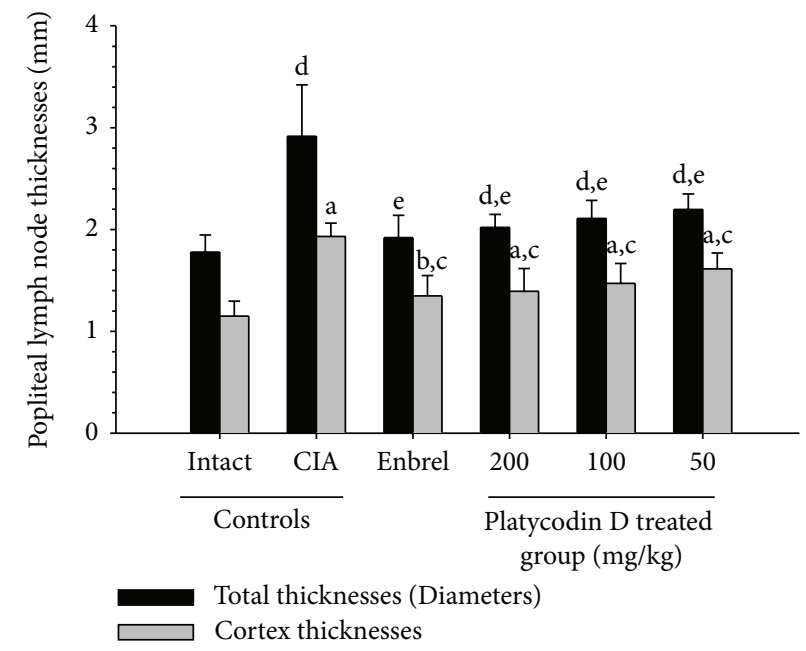

(c)

FIGURE 10: Platycodin D improved the histopathological changes of the secondary lymphatic organs. (a) The total spleen and white pulp thicknesses of platycodin D-treated mice were significantly decreased compared with the CIA control mice. Measurements of total spleen (arrow) and white pulp (dotted arrow) thicknesses are shown in Figure 8. (b) The splenic white pulp of platycodin D-treated mice was significantly lower compared with CIA control mice. (c) The popliteal lymph node total and cortex thickness of platycodin D-treated mice were significantly lower compared with the CIA control mice. Measurement of lymph node total (arrow) and cortex (dotted arrow) thicknesses are shown in Figure 9. Values are expressed as means \pm SD $(n=8) ;{ }^{a} P<0.01$ and ${ }^{b} P<0.05$ as compared with intact control by LSD test; ${ }^{\mathrm{c}} P<0.01$ as compared with CIA control by LSD test; ${ }^{\mathrm{d}} P<0.01$ as compared with intact control by MW test; ${ }^{\mathrm{e}} P<0.01$ as compared with CIA control by MW test.

enzymes released from PMNs [40]. In the present study, the increases of paw MPO levels observed in CIA control were marked inhibited by treatment of Enbrel or platycodin D. Therefore, it is considered that platycodin $\mathrm{D}$ has direct antiinflammatory effects.

Inflammations were directly correlated with oxidative stress [41] and oxidative stresses are also involved in the pathogenesis of CIA $[9,10]$. In addition, marked increases of MDA, a marker of lipid peroxidation were also reported in CIA paw [31]. In the present study, dramatically increases of paw MDA levels were also detected in CIA control mice. However, these increases of MDA contents were dosedependently inhibited by treatment of platycodin D like
Enbrel. These results suggested that platycodin D exerts antioxidant effect by inhibiting MDA.

Abnormal increases of cytokine, IL- 6 , and TNF- $\alpha$ have been involved in the pathogenesis of RA $[1,42]$. The cytokine TNF- $\alpha$, produced by a variety of cell types, including splenocytes, was found to be associated with critical events leading to T-lineage commitment and differentiation [43]. TNF- $\alpha$ can enhance the in vivo immune response at doses much lower than those that cause weight loss or tissue toxicity. It enhances proliferation of $\mathrm{B}$ and $\mathrm{T}$ cells and promotes the generation of cytotoxic $\mathrm{T}$ cells. In addition, it enhances IL2 -induced immunoglobulin production and augments IL2 stimulated natural killer cell activity and proliferation of 
monocytes [44]. IL-6 has also been proposed to contribute to the development of arthritis [45]. IL-6 is known to be present at high levels in the serum and synovial fluid of RA and juvenile RA patients [46-48]. IL-6 acts as a stimulator of both $\mathrm{B}$ and $\mathrm{T}$ cell functions; it also promotes proliferation of plasmablastic precursors in the bone marrow and their final stage of maturation into immunoglobulin-producing plasma cells and participates in the activation and proliferation of $\mathrm{T}$ cells [45]. In the present study, marked increases of paw IL- 6 and TNF- $\alpha$ contents were also observed with increases of splenocyte IL- 6 and TNF- $\alpha$ productions. However, these increases of cytokine activities and productions were dosedependently inhibited by treatment of platycodin $\mathrm{D}$ like Enbrel. These results are considered as one of indirect evidence that platycodin $\mathrm{D}$ has some immunomodulatory effects as already known [24, 25] and these immunomodulatory effects of platycodin D may involve the efficacies against the CIA detected in this study.

Clinical arthritis score system based on the gross edematous changes and inflammations have been used as a valuable scoring system to detect the efficacy of test materials on CIA [49]. In addition, poly-arthritis occurred in CIA [34, 50], and marked increases of paw and knee thicknesses were observed with significant increases of paw weights [35]. Histopathologically, inflammation of peripheral synovial joints including infiltrations of inflammatory cells, articular cartilage, and bone damages were induced in CIA, and semiquantitative score system based on these histopathological changes have been used as a valuable scoring system to detect the efficacy of test materials on CIA $[32,42,49,51,52]$. In the present study, severe inflammatory changes, cartilage, and bone erosions were observed on the knee and third hind digits of CIA control mice. Dose-dependent inhibition of these histopathological and histomorphometrical changes by treatment of platycodin $\mathrm{D}$ detected in the present study is considered as direct evidence that platycodin D has favorable effects on the CIA.

The importance of secondary lymphoid organs in the development of RA was demonstrated in early studies [53]. Generally, secondary lymphoid organs are enlarged due to hyperplasia of lymphoid cells $[54,55]$. In the present study, enhanced immunity signs [33] as increases of spleen and lymph node weights, enlargement of spleen and lymph nodes due to hyperplasia of lymphoid cells were detected in CIA control at gross and histopathological observations. These enhanced immunities were dose-dependently inhibited by treatment of platycodin D like Enbrel.

\section{Conclusion}

The results obtained in this study suggest that oral treatment of platycodin D 200, 100, and $50 \mathrm{mg} / \mathrm{kg}$ showed relatively good favorable effects on the CIA mice mediated by antiinflammatory, antioxidative, and immunomodulatory effects. These data suggest that platycodin D promise as a new effective antirheumatoid arthritis agent. Since marked favorable anti-CIA effects were also detected in platycodin D $50 \mathrm{mg} / \mathrm{kg}$ treated mice, the minimal effective dosage of platycodin $\mathrm{D}$ on CIA mice after oral administration is considered as below $50 \mathrm{mg} / \mathrm{kg}$.

\section{Conflict of Interests}

The authors declare that there are no conflict of interests.

\section{Authors' Contribution}

O. Gon Kwon and Sae Kwang Ku contributed equally to this work.

\section{Acknowledgment}

This work was supported by the National Research Foundation of Korea (NRF) Grant funded by the Korea government (MSIP) (no. 2013-067053).

\section{References}

[1] M. Feldmann, F. M. Brennan, and R. N. Maini, "Role of cytokines in rheumatoid arthritis," Annual Review of Immunology, vol. 14, pp. 397-440, 1996.

[2] M. Feldmann, F. M. Brennan, and R. N. Maini, "Rheumatoid arthritis," Cell, vol. 85, no. 3, pp. 307-310, 1996.

[3] A. Seven, S. Güzel, M. Aslan, and V. Hamuryudan, "Lipid, protein, DNA oxidation and antioxidant status in rheumatoid arthritis," Clinical Biochemistry, vol. 41, no. 7-8, pp. 538-543, 2008.

[4] S.-C. Bae, S.-J. Kim, and M.-K. Sung, "Inadequate antioxidant nutrient intake and altered plasma antioxidant status of rheumatoid arthritis patients," Journal of the American College of Nutrition, vol. 22, no. 4, pp. 311-315, 2003.

[5] M. D. McCubbin, G. Hou, G. D. Abrams, R. Dick, Z. Zhang, and G. J. Brewer, "Tetrathiomolybdate is effective in a mouse model of arthritis," Journal of Rheumatology, vol. 33, no. 12, pp. 25012506, 2006.

[6] E.-M. Choi, "Oxidative status of DBA/1J mice with type II collagen-induced arthritis," Journal of Applied Toxicology, vol. 27, no. 5, pp. 472-481, 2007.

[7] D. M. Lee and M. E. Weinblatt, "Rheumatoid arthritis," The Lancet, vol. 358, no. 9285, pp. 903-911, 2001.

[8] N. R. Slifman, S. K. Gershon, J.-H. Lee, E. T. Edwards, and M. M. Braun, "Listeria monocytogenes infection as a complication of treatment with tumor necrosis factor $\alpha$-neutralizing agents," Arthritis and Rheumatism, vol. 48, no. 2, pp. 319-324, 2003.

[9] K. Drabikova, T. Perecko, R. Nosal et al., "Glucomannan reduces neutrophil free radical production in vitro and in rats with adjuvant arthritis," Pharmacological Research, vol. 59, no. 6, pp. 399-403, 2009.

[10] F. Nagatomo, N. Gu, H. Fujino et al., "Effects of exposure to hyperbaric oxygen on oxidative stress in rats with type II collagen-induced arthritis," Clinical and Experimental Medicine, vol. 10, no. 1, pp. 7-13, 2010.

[11] H. L. Zhao, K.-H. Cho, Y. W. Ha, T.-S. Jeong, W. S. Lee, and Y. S. Kim, "Cholesterol-lowering effect of platycodin D in hypercholesterolemic ICR mice," European Journal of Pharmacology, vol. 537, no. 1-3, pp. 166-173, 2006.

[12] J. Lee, H. Kim, C. Lee et al., "Four-week repeated-dose toxicity study on Pinellia extract," Korean Journal of Laboratory Animal Science, vol. 19, pp. 127-141, 2003.

[13] L.-K. Han, B.-J. Xu, Y. Kimura, Y.-N. Zheng, and H. Okuda, "Platycodi radix affects lipid metabolism in mice with high fat 
diet-induced obesity," Journal of Nutrition, vol. 130, no. 11, pp. 2760-2764, 2000.

[14] L.-K. Han, Y.-N. Zheng, B.-J. Xu, H. Okuda, and Y. Kimura, "Saponins from Platycodi radix ameliorate high fat diet-induced obesity in mice," Journal of Nutrition, vol. 132, no. 8, pp. 2241$2245,2002$.

[15] K.-S. Kim, E.-K. Seo, Y.-C. Lee et al., "Effect of dietary Platycodon grandiflorum on the improvement of insulin resistance in obese Zucker rats," Journal of Nutritional Biochemistry, vol. 11, no. 9, pp. 420-424, 2000.

[16] H. L. Zhao, J.-S. Sim, S. H. Shim, Y. W. Ha, S. S. Kang, and Y. S. Kim, "Antiobese and hypolipidemic effects of platycodin saponins in diet-induced obese rats: evidences for lipase inhibition and calorie intake restriction," International Journal of Obesity, vol. 29, no. 8, pp. 983-990, 2005.

[17] Y. P. Kim, E. B. Lee, S. Y. Kim et al., "Inhibition of prostaglandin E2 production by platycodin D isolated from the root of Platycodon grandiflorum," Planta Medica, vol. 67, no. 4, pp. 362364, 2001.

[18] J. W. Chung, E. J. Noh, H. L. Zhao et al., "Anti-inflammatory activity of prosapogenin methyl ester of platycodin D via nuclear factor-kappaB pathway inhibition," Biological and Pharmaceutical Bulletin, vol. 31, no. 11, pp. 2114-2120, 2008.

[19] J. J. Hong, K. H. Shin, S. S. Lim et al., "Lead compounds for antiinflammatory drugs isolated from the plants of the traditional oriental medicine in Korea," Inflammation and Allergy, vol. 7, no. 3, pp. 195-202, 2008.

[20] M.-O. Kim, D.-O. Moon, H. C. Yung, J.-D. Lee, D. K. Nam, and G.-Y. Kim, "Platycodin D induces mitotic arrest in vitro, leading to endoreduplication, inhibition of proliferation and apoptosis in leukemia cells," International Journal of Cancer, vol. 122, no. 12, pp. 2674-2681, 2008.

[21] J. S. Yu and A. K. Kim, "Platycodin D induces apoptosis in MCF7 human breast cancer cells," Journal of Medicinal Food, vol. 13, no. 2, pp. 298-305, 2010.

[22] S.-S. Choi, E.-J. Han, T.-H. Lee et al., "Antinociceptive mechanisms of platycodin D administered intracerebroventricularly in the mouse," Planta Medica, vol. 68, no. 9, pp. 794-798, 2002.

[23] S.-S. Choi, E.-J. Han, T.-H. Lee, K.-J. Han, H.-K. Lee, and H.W. Suh, "Antinociceptive profiles of platycodin D in the mouse," American Journal of Chinese Medicine, vol. 32, no. 2, pp. 257268, 2004.

[24] Y. Xie, H.-X. Sun, and D. Li, "Platycodin D is a potent adjuvant of specific cellular and humoral immune responses against recombinant hepatitis B antigen," Vaccine, vol. 27, no. 5, pp. 757764, 2009.

[25] Y. Xie, H.-X. Sun, and D. Li, "Platycodin D improves the immunogenicity of newcastle disease virus-based recombinant avian influenza vaccine in mice," Chemistry and Biodiversity, vol. 7, no. 3, pp. 677-689, 2010.

[26] I. o. L. A. Resources, Guide for the Care and Use of Laboratory Animals, National Academies Press, 1996.

[27] D. E. Trentham, A. S. Townes, and A. H. Kang, "Autoimmunity to type II collagen: an experimental model of arthritis," Journal of Experimental Medicine, vol. 146, no. 3, pp. 857-868, 1977.

[28] E. Brahn, M. L. Banquerigo, G. S. Firestein, D. L. Boyle, A. L. Salzman, and C. Szabó, "Collagen induced arthritis: reversal by mercaptoethylguanidine, a novel antiinflammatory agent with a combined mechanism of action," Journal of Rheumatology, vol. 25, no. 9, pp. 1785-1793, 1998.
[29] L. Liaudet, J. G. Mabley, P. Pacher et al., "Inosine exerts a broad range of antiinflammatory effects in a murine model of acute lung injury," Annals of Surgery, vol. 235, no. 4, pp. 568-578, 2002.

[30] M. M. Bradford, "A rapid and sensitive method for the quantitation of microgram quantities of protein utilizing the principle of protein dye binding," Analytical Biochemistry, vol. 72, no. 1-2, pp. $248-254,1976$.

[31] J. G. Mabley, L. Liaudet, P. Pacher, G. J. Southan, A. L. Salzman, and C. Szabó, "Part II: beneficial effects of the peroxynitrite decomposition catalyst FP15 in murine models of arthritis and colitis," Molecular Medicine, vol. 8, no. 10, pp. 581-590, 2002.

[32] M.-L. Cho, Y.-J. Heo, M.-K. Park et al., "Grape seed proanthocyanidin extract (GSPE) attenuates collagen-induced arthritis," Immunology Letters, vol. 124, no. 2, pp. 102-110, 2009.

[33] H.-S. Yoon, J.-W. Kim, H.-R. Cho et al., "Immunomodulatory effects of Aureobasidium pullulans SM-2001 exopolymers on the cyclophosphamide-treated mice," Journal of Microbiology and Biotechnology, vol. 20, no. 2, pp. 438-445, 2010.

[34] C. Larsen, J. Østergaard, S. W. Larsen et al., "Intra-articular depot formulation principles: role in the management of postoperative pain and arthritic disorders," Journal of Pharmaceutical Sciences, vol. 97, no. 11, pp. 4622-4654, 2008.

[35] J. Ishikawa, Y. Okada, I. N. Bird, B. Jasani, J. H. Spragg, and T. Yamada, "Use of anti-platelet-endothelial cell adhesion molecule-1 antibody in the control of disease progression in established collagen-induced arthritis in DBA/1J mice," Japanese Journal of Pharmacology, vol. 88, no. 3, pp. 332-340, 2002.

[36] P. Zhu, X.-Y. Li, H.-K. Wang et al., "Oral administration of type-II collagen peptide 250-270 suppresses specific cellular and humoral immune response in collagen-induced arthritis," Clinical Immunology, vol. 122, no. 1, pp. 75-84, 2007.

[37] F. Wolfe and D. J. Hawley, "The longterm outcomes of rheumatoid arthritis: work disability: a prospective 18 year study of 823 patients," Journal of Rheumatology, vol. 25, no. 11, pp. 2108-2117, 1998.

[38] B. J. Zimmerman, M. B. Grisham, and D. N. Granger, "Role of oxidants in ischemia/reperfusion-induced granulocyte infiltration," American Journal of Physiology-Gastrointestinal and Liver Physiology, vol. 258, no. 2, pp. G185-G190, 1990.

[39] G. W. Sullivan, I. J. Sarembock, and J. Linden, "The role of inflammation in vascular diseases," Journal of Leukocyte Biology, vol. 67, no. 5, pp. 591-602, 2000.

[40] S. Ö. Íşeri, G. Şener, M. Yüksel et al., "Ghrelin against alendronate-induced gastric damage in rats," Journal of Endocrinology, vol. 187, no. 3, pp. 399-406, 2005.

[41] H. S. Lee and S. K. Ku, "Effects of Picrorrhiza Rhizoma on acute inflammation in mice," Biomolecules \& Therapeutics, vol. 16, no. 2, pp. 137-140, 2008.

[42] Y. Nozaki, T. Yamagata, M. Sugiyama, S. Ikoma, K. Kinoshita, and M. Funauchi, "Anti-inflammatory effect of all-transretinoic acid in inflammatory arthritis," Clinical Immunology, vol. 119, no. 3, pp. 272-279, 2006.

[43] S. Samira, C. Ferrand, A. Peled et al., "Tumor necrosis factor promotes human T-cell development in nonobese diabetic/severe combined immunodeficient mice," Stem Cells, vol. 22, no. 6, pp. 1085-1100, 2004.

[44] I. R. Tizard, Immunology: An Introduction, Saunders College Publishing, Philadelphia, Pa, USA, 4th edition, 1995.

[45] J. Van Snick, "Interleukin-6: an overview," Annual Review of Immunology, vol. 8, pp. 253-278, 1990. 
[46] E. Lupia, G. Montrucchio, E. Battaglia, V. Modena, and G. Camussi, "Role of tumor necrosis factor- $\alpha$ and plateletactivating factor in neoangiogenesis induced by synovial fluids of patients with rheumatoid arthritis," European Journal of Immunology, vol. 26, no. 8, pp. 1690-1694, 1996.

[47] G. Sethi, B. Sung, A. B. Kunnumakkara, and B. B. Aggarwal, "Targeting TNF for treatment of cancer and autoimmunity," Advances in Experimental Medicine and Biology, vol. 647, pp. 3751, 2009.

[48] D. H. Zimmerman, P. Taylor, A. Bendele et al., "CEL-2000: a therapeutic vaccine for rheumatoid arthritis arrests disease development and alters serum cytokine/chemokine patterns in the bovine collagen type II induced arthritis in the DBA mouse model," International Immunopharmacology, vol. 10, no. 4, pp. 412-421, 2010.

[49] S. H. Mun, H. S. Kim, J. W. Kim et al., "Oral administration of curcumin suppresses production of matrix metalloproteinase (MMP)-1 and MMP-3 to ameliorate collagen-induced arthritis: inhibition of the PKC $\delta / J \mathrm{NK} / \mathrm{c}$-Jun pathway," Journal of Pharmacological Sciences, vol. 111, no. 1, pp. 13-21, 2009.

[50] E. H. S. Choy and G. S. Panayi, "Cytokine pathways and joint inflamation in rheumatoid arthritis," The New England Journal of Medicine, vol. 344, no. 12, pp. 907-916, 2001.

[51] Y. Ono, M. Inoue, H. Mizukami, and Y. Ogihara, "Suppressive effect of Kanzo-bushi-to, a Kampo medicine, on collageninduced arthritis," Biological and Pharmaceutical Bulletin, vol. 27, no. 9, pp. 1406-1413, 2004.

[52] J.-D. Lee, J.-E. Huh, Y.-H. Baek, K.-C. Cho, D.-Y. Choi, and D.-S. Park, "The efficacy and mechanism action of rvcsd, a new herbal agent, on immune suppression and cartilage protection in a mouse model of rheumatoid arthritis," Journal of Pharmacological Sciences, vol. 109, no. 2, pp. 211-221, 2009.

[53] B. B. Newbould, "Lymphatic drainage and adjuvant-induced arthraitis in rats," British Journal of Experimental Pathology, vol. 45, pp. 375-383, 1964.

[54] D. Lorton, C. Lubahn, S. Y. Felten, and D. Bellinger, "Norepinephrine content in primary and secondary lymphoid organs is altered in rats with adjuvant-induced arthritis," Mechanisms of Ageing and Development, vol. 94, no. 1-3, pp. 145-163, 1997.

[55] Y.-C. Lee, S.-H. Kim, S.-S. Roh, H.-Y. Choi, and Y.-B. Seo, "Suppressive effects of Chelidonium majus methanol extract in knee joint, regional lymph nodes, and spleen on collageninduced arthritis in mice," Journal of Ethnopharmacology, vol. 112, no. 1, pp. 40-48, 2007. 


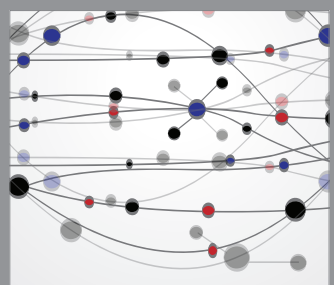

The Scientific World Journal
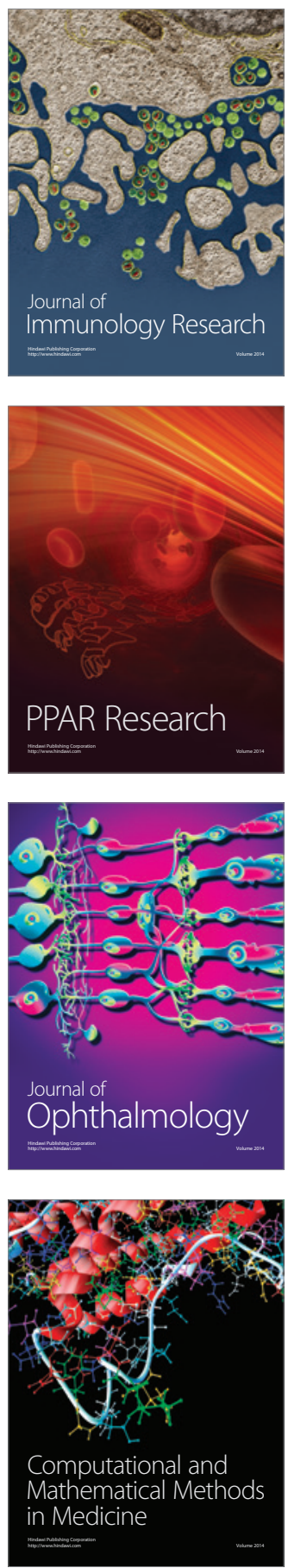

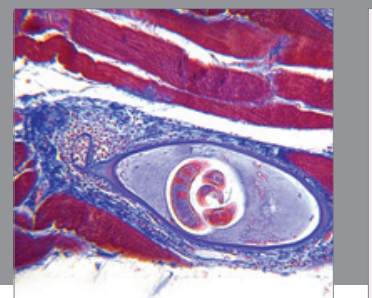

Gastroenterology

Research and Practice
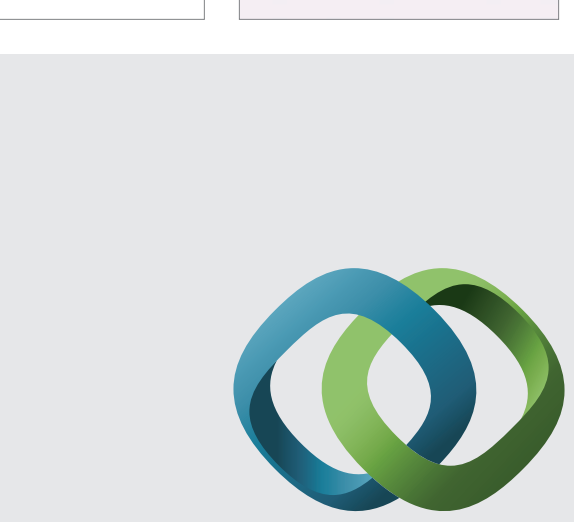

\section{Hindawi}

Submit your manuscripts at

http://www.hindawi.com
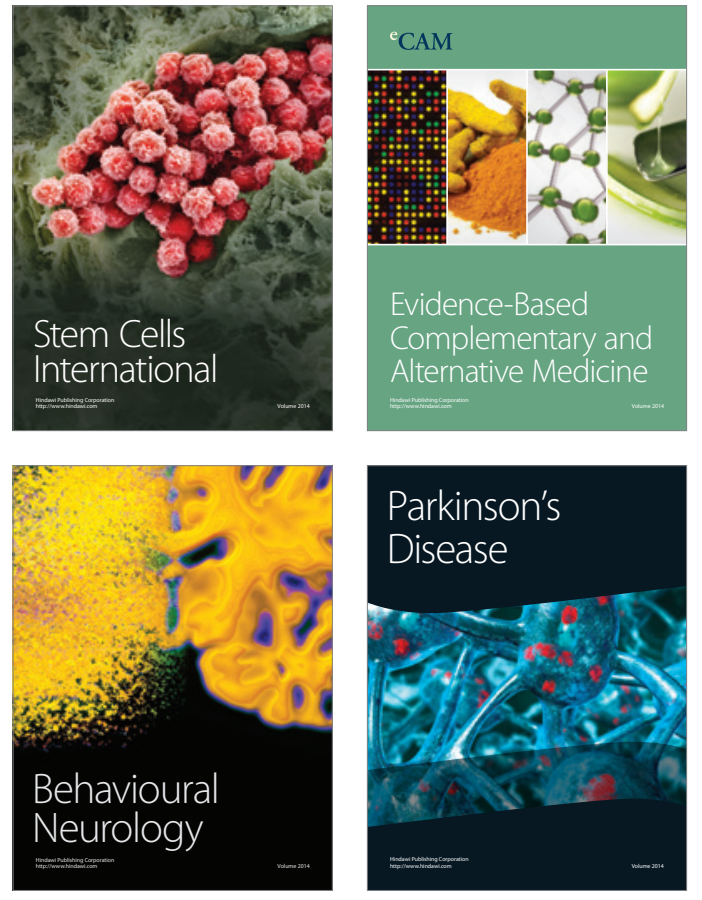
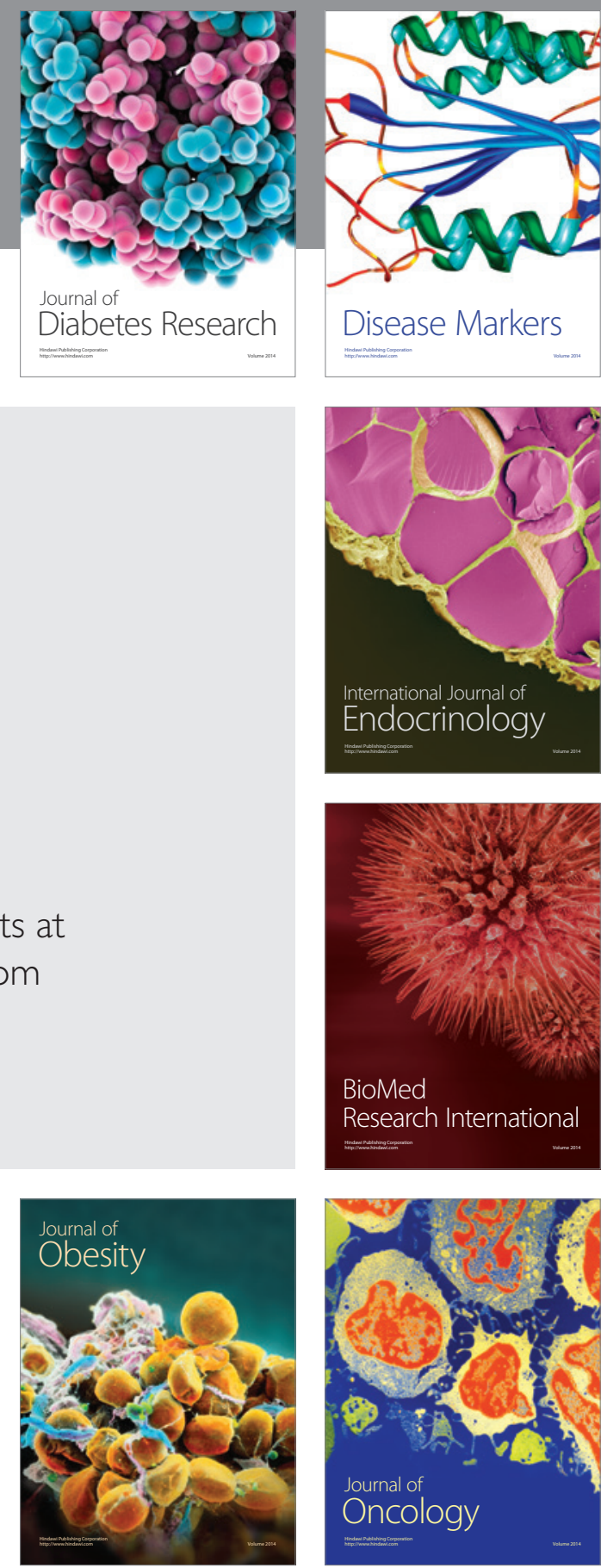

Disease Markers
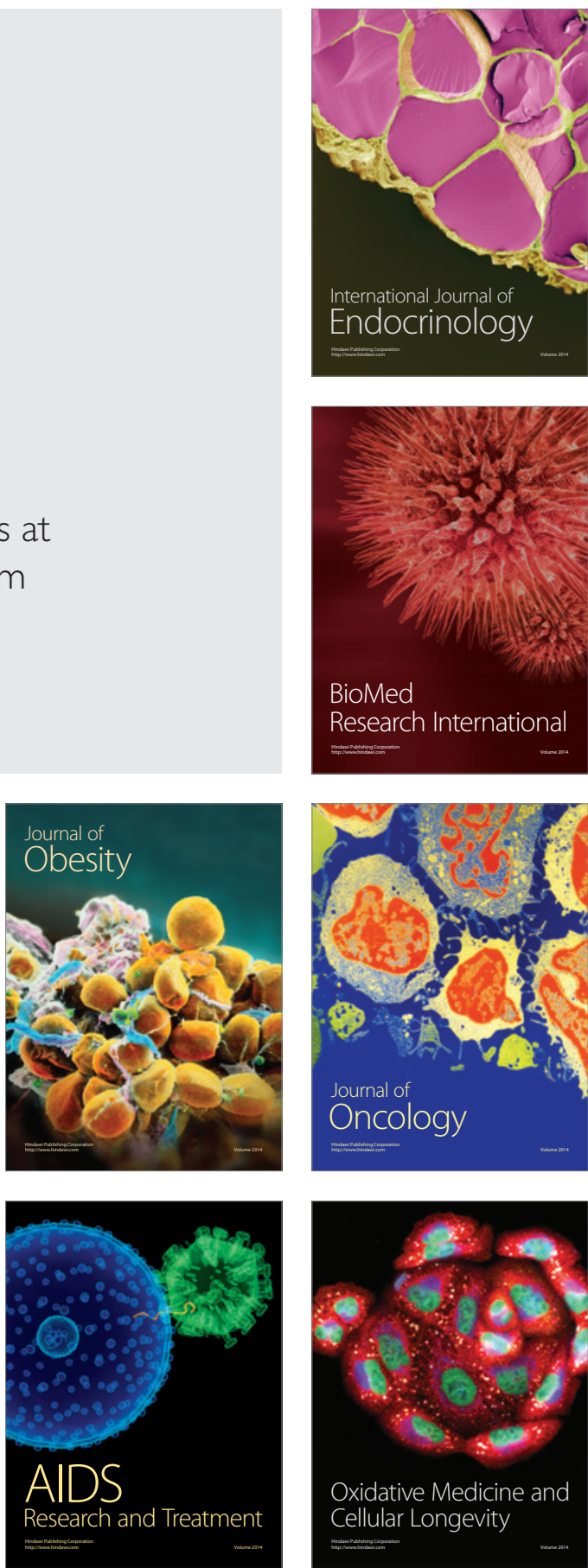